\title{
MONETARY AND FISCAL
} POLICY INTERACTIONS IN A NEW KEYNESIAN MODEL WITH CAPITAL ACCUMULATION AND NON-RICARDIAN CONSUMERS

by Campbell Leith and Leopold von Thadden 
EUROPEAN CENTRAL BANK

\section{WORKING PAPER SERIES}

NO 649 I JUNE 2006

\section{MONETARY AND FISCAL POLICY INTERACTIONS IN A NEW KEYNESIAN MODEL WITH CAPITAL ACCUMULATION AND NON-RICARDIAN CONSUMERS}

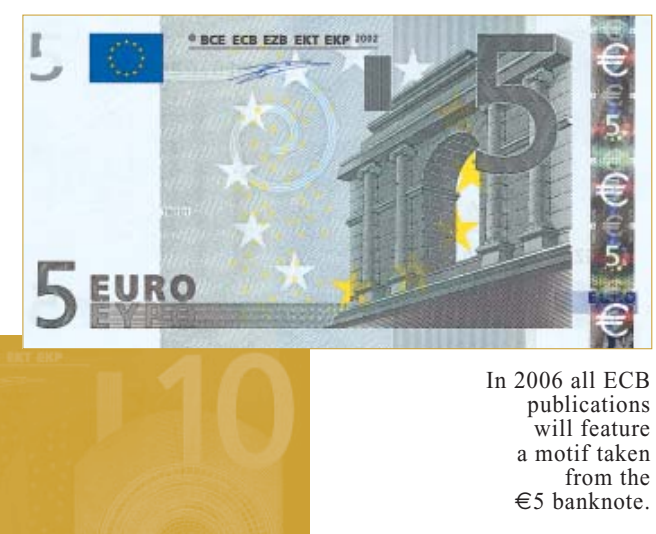

by Campbell Leith ${ }^{2}$ and Leopold von Thadden ${ }^{3}$

This paper can be downloaded without charge from http://www.ecb.int or from the Social Science Research Network electronic library at http://ssrn.com/abstract_id $=908620$

I Comments on an early version of this paper by Martin Ellison, George von Fuerstenberg, Heinz Herrmann, Leo Kaas, Jana Kremer, Eric Leeper, Massimo Rostagno, Andreas Schabert, Harald Uhlig as well as seminar participants at the European Central Bank, the Deutsche Bundesbank, the University of Konstanz, the CEPR-conference on "The implications of alternative fiscal rules for monetary policy" (Helsinki, 2004), and at the annual meetings of the Econometric Society (Madrid, 2004), the German Economic Association (Dresden, 2004), and the Royal Economic Society (Nottingham, 2005) are gratefully acknowledged.

The views expressed in this paper are those of the authors and do not necessarily reflect the views of the European Central Bank. 2 Department of Economics, Adam Smith Building, University of Glasgow, Glasgow GI 2 8RT, United Kingdom; e-mail:c.b.leith@socsci.gla.ac.uk 
(C) European Central Bank, 2006

\section{Address}

Kaiserstrasse 29

60311 Frankfurt am Main, Germany

\section{Postal address}

Postfach 160319

60066 Frankfurt am Main, Germany

\section{Telephone}

+496913440

\section{Internet}

http://www.ecb.int

\section{Fax}

+496913446000

\section{Telex}

$411144 \mathrm{ecb} d$

All rights reserved.

Any reproduction, publication and reprint in the form of a different publication, whether printed or produced electronically, in whole or in part, is permitted only with the explicit written authorisation of the ECB or the author(s).

The views expressed in this paper do not necessarily reflect those of the European Central Bank.

The statement of purpose for the ECB Working Paper Series is available from the ECB website, http://www.ecb.int.

ISSN 1561-0810 (print)

ISSN 1725-2806 (online) 


\section{CONTENTS}

Abstract

Non-technical summary 5

1 Introduction 7

2 The Model 10

2.1 Problem of the representative consumer $\quad 10$

2.2 Aggregate behavior of consumers $\quad 12$

2.3 Problems of the representative firms $\quad$ I2

2.3.1 Capital rental firms I3

2.3.2 Final Goods Producers || 3

2.4 The government 14

2.5 Summary of equilibrium conditions $\quad$ | 5

3 Steady states 16

3.1 Existence 16

3.2 Local dynamics 18

4 Classification of local equilibrium dynamics $\quad \| 9$

4.1 Ricardian consumers $(\xi=0) \quad 19$

4.1.1 Monetary dynamics 20

4.1.2 Monetary and fiscal dynamics 2 I

4.2 Non-Ricardian consumers $(\xi>0) \quad 22$

4.2.1 Efficient steady states 22

4.2.2 Inefficient steady states 25

5 Endogenous labour supply of Ricardian consumers

6 Conclusion 29

Appendix 30

References 34

European Central Bank Working Paper Series 37 


\begin{abstract}
This paper develops a small New Keynesian model with capital accumulation and government debt dynamics. The paper discusses the design of simple monetary and fiscal policy rules consistent with determinate equilibrium dynamics in the absence of Ricardian equivalence. Under this assumption, government debt turns into a relevant state variable which needs to be accounted for in the analysis of equilibrium dynamics. The key analytical finding is that without explicit reference to the level of government debt it is not possible to infer how strongly the monetary and fiscal instruments should be used to ensure determinate equilibrium dynamics. Specifically, we identify in our model discontinuities associated with threshold values of steady-state debt, leading to qualitative changes in the local determinacy requirements. These features extend the logic of Leeper (1991) to an environment in which fiscal policy is non-neutral. Naturally, this non-neutrality increases the importance of fiscal aspects for the design of policy rules consistent with determinate dynamics.
\end{abstract}

Keywords: Monetary policy, Fiscal regimes.

JEL classification numbers: E52, E63. 


\section{Non-technical summary}

The literature on the desirable design of macroeconomic policies typically concludes that operational policy rules should not be a source of non-fundamental fluctuations in economic activity, implying that the induced rational expectations equilibrium should be at least locally unique. While this criterion for a good policy design is widely shared, the literature exhibits a remarkable asymmetry with respect to the analysis of monetary and fiscal aspects of policy rules. Monetary policy rules, typically specified as interest rate rules with feedbacks to endogenous variables like inflation or output, have been analyzed in great analytical detail. But there is no similarly rich literature on the appropriate use of fiscal instruments.

This asymmetric treatment is adequate in many commonly used models in which fiscal policy acts through variations in lump-sum taxes in an environment of Ricardian equivalence. In line with the logic spelled out in Leeper (1991), the joint design problem of monetary and fiscal policy-making then essentially reduces to two separable problems which can be recursively addressed. First, isolated from fiscal aspects, there are monetary aspects, as witnessed by the large literature on the Taylor principle which typically establishes conditions for local equilibrium determinacy solely in terms of monetary policy parameters. Second, if the monetary dynamics are determinate, there is no 'active' role for fiscal policy, i.e. the determinacy feature remains preserved if government debt dynamics evolve 'passively' in a stable manner. If, however, the dynamic system without fiscal policy exhibits one degree of indeterminacy, then potentially unstable debt dynamics are needed to restore equilibrium determinacy, consistent with Leeper's notion of 'active' fiscal policy or, alternatively, with the view of the 'fiscal theory of the price level' expressed in Woodford (1994) and Sims (1994).

The main contribution of this paper is to show how this logic needs to be modified in an environment which departs from Ricardian equivalence, implying that equilibrium dynamics are driven by a genuine interaction of monetary and fiscal policy. To this end, we develop a tractable New Keynesian model in which wealth effects of government debt are not restricted to the intertemporal budget constraint of the government but fully interact with all remaining equilibrium conditions of the economy. This implies that government debt turns into a relevant state variable which needs to be accounted for in the analysis of local equilibrium dynamics.

In our analysis, the 'relevance' of government debt translates into two findings. First, without explicit reference to the steady-state level of government debt it is not possible to infer how strongly the monetary and fiscal instruments within simple feedback rules should be used to ensure locally determinate equilibrium dynamics. Second, the determinacy regions depend on the 
underlying level of debt in a discontinuous way such that the determinacy conditions undergo qualitative changes at certain threshold values of steady-state debt. Reflecting the assumed nonneutrality of fiscal policy, these two features overturn the logic of separable monetary and fiscal dynamics as sketched above and lead overall to a more symmetric treatment of monetary and fiscal policy aspects. 


\section{Introduction}

The literature on the desirable design of macroeconomic policies typically concludes that operational policy rules should not be a source of non-fundamental fluctuations in economic activity, implying that the induced rational expectations equilibrium should be at least locally unique. While this criterion for a good policy design is widely shared, the literature exhibits a remarkable asymmetry with respect to the analysis of monetary and fiscal aspects of policy rules. Monetary policy rules, typically specified as interest rate rules with feedbacks to endogenous variables like inflation or output, have been analyzed in great analytical detail. ${ }^{1}$ But there is no similarly rich literature on the appropriate use of fiscal instruments.

This asymmetric treatment is adequate in many commonly used models in which fiscal policy acts through variations in lump-sum taxes in an environment of Ricardian equivalence. In line with the logic spelled out in Leeper (1991), the joint design problem of monetary and fiscal policy-making then essentially reduces to two separable problems which can be recursively addressed. First, isolated from fiscal aspects, there are monetary aspects, as witnessed by the large literature on the Taylor principle (Taylor, 1993) which typically establishes conditions for local equilibrium determinacy solely in terms of monetary policy parameters. Second, if the monetary dynamics are determinate, there is no 'active' role for fiscal policy, i.e. the determinacy feature remains preserved if government debt dynamics evolve 'passively' in a stable manner. If, however, the dynamic system without fiscal policy exhibits one degree of indeterminacy, then potentially unstable debt dynamics are needed to restore equilibrium determinacy, consistent with Leeper's notion of 'active' fiscal policy or, alternatively, with the view of the 'fiscal theory of the price level' expressed in Woodford (1994), Sims (1994), and Woodford (2003, ch. 4.4).

The main contribution of this paper is to show how this logic needs to be modified in an environment which departs from Ricardian equivalence, implying that equilibrium dynamics are driven by a genuine interaction of monetary and fiscal policy. To this end, we develop a tractable New Keynesian model in which wealth effects of government debt are not restricted to the intertemporal budget constraint of the government but fully interact with all remaining equilibrium conditions of the economy. This implies that government debt turns into a relevant state variable which needs to be accounted for in the analysis of local equilibrium dynamics. ${ }^{2}$ In our analysis, the 'relevance' of government debt translates into two findings. First, without explicit reference to the steady-state level of government debt it is not possible to infer how strongly the monetary and fiscal instruments within simple feedback rules should be used to ensure locally determinate equilibrium dynamics. Second, the determinacy regions depend on the underlying level of debt in a discontinuous way such that the determinacy conditions undergo qualitative changes at certain threshold values of steady-state debt. Reflecting the assumed non-neutrality of fiscal policy, these two features overturn the logic of separable monetary and fiscal dynamics as

\footnotetext{
${ }^{1}$ For representative treatments, see Taylor (1993), Kerr and King (1996), Bernanke and Woodford (1997), Clarida et al. (1999, 2000), Benhabib et al. (2001a, b), and Woodford (2003).

${ }^{2}$ We do not adress dynamic properties from a global perspective. Moreover, to allow for an exlusive focus on government debt, real balances are assumed to be a negligible fraction of total government liabilities.
} 
sketched above and lead overall to a more symmetric treatment of monetary and fiscal policy aspects.

To make this reasoning precise, the analysis builds on a New Keynesian version of the model of Blanchard (1985) in which, assuming that all taxation is lump-sum, departures from Ricardian equivalence can be conveniently modelled through a change in a single parameter, the probability of death of consumers. Specifically, Ricardian equivalence ceases to hold whenever this probability is assumed to be strictly positive, i.e. if consumers are 'non-Ricardian'. ${ }^{3}$ Because of the short-sightedness of non-Ricardian consumers, government debt affects aggregate consumption dynamics via the Euler equation, and government debt dynamics are no longer separable from the remaining equilibrium conditions. Monetary and fiscal policy are assumed to follow two stylized rules with a deliberately simple feedback structure. Monetary policy follows an interest rate rule which specifies how the monetary instrument (i.e. the interest rate) reacts to deviations of actual inflation from a target level of inflation. The single policy parameter of this rule is the 'Taylor-coefficient' on inflation, and monetary policy is called 'active' ('passive') if this coefficient is larger than unity, i.e. if the real interest rate rises (falls) in the inflation rate. Fiscal policy follows a debt targeting rule which specifies how the unique fiscal instrument (i.e. the lump-sum tax rate) reacts to deviations of the actual level of real government debt from a target level of debt. The single policy parameter of this rule is the feedback coefficient of taxes on debt. In line with Leeper (1991) and, among others, Sims (1998), Schmitt-Grohé and Uribe (2004), and Davig and Leeper (2005), we call the fiscal rule 'passive' ('active') if this coefficient is larger (smaller) than the steady-state real interest rate. ${ }^{4}$

If consumers are non-Ricardian, our analysis of local steady-state dynamics shows that there exist, depending on the assumed target level of government debt, two distinct stability regimes characterized by 'low' and 'high' steady-state levels of debt. ${ }^{5}$ In both regimes, local determinacy regions are not separated by the demarcation lines of active vs. passive fiscal policy-making. Moreover, the two regimes have the feature that there always exist regions of the parameter space (in terms of the two feedback parameters of the policy rules) which ensure determinate dynamics at 'low debt' steady states, but not at 'high debt' steady states, and vice versa. This feature makes it impossible to infer the ranges of activism and passivism of both instruments consistent with local equilibrium determinacy without explicit reference to the prevailing target level of government debt. Intuitively, in our economy the level of debt fully captures the non-neutrality of fiscal policy through

\footnotetext{
${ }^{3}$ For the same terminology, see Cushing (1999). In a related, but not identical specification Gali et al. (2004) consider 'rule-of-thumb consumers' who intertemporally can neither borrow nor save. Frequently, the literature refers to this type of consumers also as 'non-Ricardian'.

${ }^{4}$ If defined in this way, a passive fiscal policy ensures under Ricardian equivalence that government debt dynamics per se are not explosive, while under an active rule locally stable debt dynamics require the adjustment of some other variable, like a change in the price level.

${ }^{5}$ Throughout the analysis, government expenditures are specified as exogenous and changes in the steady-state level of debt result from variations in the target level of the lump-sum tax rate. Hence, we do not compare local dynamics between different fiscal instruments (i.e. between different fiscal closure rules), as done, for example, in Michel et al. (2006). The assumption of exogenously specified government expenditures makes it particularly tractable to analyze the role of wealth effects if consumers are nonRicardian.
} 
the associated wealth effect in the Euler equation. The relative importance of this wealth effect, however, varies in the level of debt. In particular, since the process of capital formation is endogenous in the model of Blanchard (1985), there exists a link between the steady-state level of debt and the degree of crowding out of capital. This in turn affects the steady-state real interest rate which is a key input for the marginal cost schedule of firms. In other words, when the capital stock is endogenous, wealth effects of government debt lead to non-trivial demand and supply effects which allow for qualitatively distinct dynamics at low and high levels of steady-state debt. Specifically, in a sense to be made precise below, our model implies that in the high (low) debt regime the required degree of fiscal discipline increases (decreases) if monetary policy becomes more active. Finally, we show that this classification of local equilibrium needs further modifications if one also allows for inefficient steady states. ${ }^{6}$

These rich findings contrast strongly with a regime of 'Ricardian' consumers, characterized by the limiting assumption of a zero probability of death. In this regime, the wealth effect of government debt in the Euler equation vanishes and the economy converges to a Ramsey-economy characterized by Ricardian equivalence and separable fiscal dynamics. Consequently, government debt is no longer an informative state variable and local determinacy regions are separated by the demarcation lines of active vs. passive fiscal policy-making, independently of the target level of government debt.

Our paper links to the related literature in a number of ways. First, it needs to be emphasized that the usage of the terms 'active' and 'passive' policy-making, unfortunately, is far from uniform in the literature. In particular, Leeper (1991) himself motivates his analysis from a generic definition which classifies a policy as passive (active) if it shows an (un)responsive reaction to current budgetary conditions. This leads him to the conclusion that "a unique pricing function requires that at least one policy authority sets its control variable actively, while an intertemporally balanced government budget requires that at least one authority sets its control variable passively". ${ }^{7}$ From the perspective of such a more encompassing definition, active and passive policy reactions, if considered outside the particular structure of Leeper's model, are no longer necessarily linked to constant threshold values of the feedback parameters in both policy rules. In principle, it would be possible to reclassify our determinacy regions along these lines. However, this would not affect our main result that under non-Ricardian consumers any such reclassification would be conditional on the level of steady-state debt under consideration.

Second, a number of recent papers have addressed aspects of non-neutral fiscal policies from a related perspective. Cushing (1999), Leith and Wren-Lewis (2000), Benassy (2005), and Chadha and Nolan (2006) all consider versions of Blanchard (1985) and Weil (1991) to discuss various properties of monetary and fiscal policy rules in environments which depart from Ricardian equivalence. All these studies, however, abstract from capital stock

\footnotetext{
${ }^{6}$ Such steady states exist since the steady-state relationship between lump-sum taxes and debt turns out to be non-monotic beyond a certain threshold value. Beyond this value, the target level of debt no longer summarizes all the relevant information on which characterizations of stabilization policies should be conditioned. Instead, the target levels of both taxes and debt need to be made explicit.

${ }^{7}$ Leeper (1991, p. 132). For a similarly broad generic definition, see Woodford (2003, ch.4.4) who refers, however, to the complementary terminology of Ricardian vs. non-Riardian fiscal policies.
} 
dynamics. Because of this feature, supply-side patterns are less rich and none of the studies reports the existence of thresholds levels of debt which lead to qualitative changes in the dynamic properties of the economy, as established in this paper.

Using standard Ramsey-type set-ups, Edge and Rudd (2002) and Linnemann (2006) consider New Keynesian economies in which fiscal policy is non-neutral because of distortionary taxation. Both papers show that this modification, conditional on the nature and the degree of the distortion, changes the benchmark of the Taylor principle, but there is no explicit reference to the role of debt. In similar spirit, Canzoneri and Diba (2005) give fiscal policy a non-neutral role by assuming that government bonds provide transaction services. Similar to our conclusion, the paper offers numerical results which show that the aggressiveness of monetary policy which is needed to ensure locally determinate dynamics depends non-trivially on fiscal parameters, but the paper does not report a systematic role of government debt in this context. Davig and Leeper (2005) extend the original contribution of Leeper (1991) to an environment with switching regimes which cover all four combinations of active and passive monetary and fiscal policy-making. This feature implies that shocks to fiscal policy affect the dynamics of the price level even if the regime currently in place would suggest that Ricardian equivalence is satisfied.

Third, our paper relates to the growing literature on monetary policy and capital accumulation, as recently summarized in Benhabib et al. (2005). In particular, because of the continuous time dimension of the model of Blanchard (1985), our findings can be related to Dupor (2001) and Carlstrom and Fuerst (2005), and we address this relationship in a separate discussion in Section 5.

The remainder of this paper proceeds as follows. Section 2 develops the model economy. Section 3 establishes the existence of steady states and summarizes the equations which govern local dynamics around steady states. Section 4 derives the main results of the paper on the determinacy of equilibria. Section 5 offers a self-contained discussion of critical aspects of the labour supply specification. Section 6 concludes. Technical parts and proofs are delegated to the Appendix.

\section{The Model}

Consumers are specified as in Blanchard (1985) in that they face a constant probability of death, denoted by $\xi \geq 0$. If this probability is positive $(\xi>0)$, the effective decision horizon of private agents is shorter than of the government and the model differs through this channel from a standard Ramsey-type infinite horizon economy. The latter type of economy, however, can be discussed as a special case if one considers a zero probability of death $(\xi=0)$.

\subsection{Problem of the representative consumer}

A consumer born at time $j$ has a constant time endowment of unity per period. In a representative period, he chooses consumption $\left(c_{s}^{j}\right)$ and real money balances $\left(m_{s}^{j}\right)$ in order to maximize his intertemporal utility function, taking as given the rate of time preference 
$\theta$ and a constant probability of death $\xi .8$ The individual labour supply is inelastically fixed at $n_{s}^{j}=1$. We allow for three distinct assets: physical capital, interest-bearing government debt, and real balances. Later on, when studying the dynamics of the economy, we consider for simple tractability the cashless-limit. To this end, it is convenient to assume that real balances enter the utility function of agents in an additively separable manner. Expected utility of the consumer at time $t$ reads as

$$
E_{t} U^{j}=\int_{t}^{\infty}\left[\ln c_{s}^{j}+\chi \ln m_{s}^{j}\right] \cdot e^{-(\xi+\theta)(s-t)} d s,
$$

where $\chi$ governs the share of real balances in the consumer's portfolio (and $\chi \rightarrow 0$ corresponds to the cashless limit). The consumer holds real non-human wealth $a_{s}^{j}=k_{s}^{j}+b_{s}^{j}+m_{s}^{j}$, consisting of physical capital $\left(k_{s}^{j}\right)$, real government bonds $\left(b_{s}^{j}\right)$, and real balances. The consumer's flow budget constraint is given by,

$$
d a_{s}^{j}=r_{s}\left(a_{s}^{j}-m_{s}^{j}\right)+\xi a_{s}^{j}+w_{s}-\tau_{s}^{j}-c_{s}^{j}-\pi_{s} m_{s}^{j}+\Omega_{s}^{j} .
$$

Physical capital and real government bonds are perfect substitutes, earning the same riskless real rate of return $r_{s}$, while real balances depreciate at the rate of inflation $\pi_{s}$. As consumers do not live forever, competitive insurance companies are prepared to pay a premium $\xi a_{s}^{j}$ in each period in return for obtaining the non-human wealth of consumers in the case of death. The individual is paid a real wage of $w_{s}$ and is subject to a lumpsum tax $\tau_{s}^{j}$. Consumers also receive a share of the profits of final goods producers of $\Omega_{s}^{j}$, to be derived below. The first-order condition for consumption is given by $c_{s}^{j}=1 / \lambda_{s}^{j}$, where $\lambda_{s}^{j}$ denotes the co-state variable from the current value Hamiltonian used to solve the consumer's problem. Real balances satisfy $\chi / m_{s}^{j}=\lambda_{s}^{j}\left(r_{s}+\pi_{s}\right)$, leading to the money demand equation $m_{s}^{j}=\chi c_{s}^{j} /\left(r_{s}+\pi_{s}\right)$. The co-state variable evolves over time according to $d \lambda_{s}^{j}=-\left(r_{s}-\theta\right) \lambda_{s}^{j}$, implying the law of motion for individual consumption dynamics $d c_{s}^{j}=$ $\left(r_{s}-\theta\right) c_{s}^{j}$. Integrating the flow budget constraint and imposing the transversality-condition regarding non-human wealth (i.e. $\lim _{s \rightarrow \infty} a_{s}^{j} \cdot e^{-\int_{t}^{s}\left(r_{\mu}+\xi\right) d \mu}=0$ ), the intertemporal budget constraint can be written as

$$
\int_{t}^{\infty} c_{s}^{j} \cdot e^{-\int_{t}^{s}\left(r_{\mu}+\xi\right) d \mu} d s=\frac{1}{1+\chi}\left(a_{t}^{j}+h_{t}^{j}\right)
$$

where $h_{t}^{j}$ is the individual's human wealth

$$
h_{t}^{j}=\int_{t}^{\infty}\left(w_{s}+\Omega_{s}^{j}-\tau_{s}\right) \cdot e^{-\int_{t}^{s}\left(r_{\mu}+\xi\right) d \mu} d s
$$

Integrating the law of motion for $c_{s}^{j}$ forward (in order to express $c_{s}^{j}$ as a function of $c_{t}^{j}$ ), one obtains from the intertemporal budget constraint the individual consumption function $c_{t}^{j}=(\xi+\theta)\left(a_{t}^{j}+h_{t}^{j}\right) /(1+\chi)$.

\footnotetext{
${ }^{8}$ As to be discussed below, $c_{s}^{j}$ denotes a consumption index of the Dixit-Stiglitz-type, i.e. final output is produced in terms of differentiated goods (along the unit interval) and $p_{s}$ stands for the corresponding aggregate price index.
} 


\subsection{Aggregate behavior of consumers}

Following Blanchard, it is convenient to normalize the population size (and, hence, the labour force) by assuming that at any moment in time a new cohort is born of size $\xi$. Any such cohort born at $j$ has a size, as of time $t$, of $\xi \cdot e^{-\xi(t-j)}$. Then, the size of the total population will always be unity, since $\int_{-\infty}^{t} \xi \cdot e^{-\xi(t-j)} d j=1$, implying $n_{t}=1$ for all $t$. Integrating over individuals of all cohorts yields the aggregate consumption and money demand functions, respectively

$$
\begin{aligned}
c_{t} & =\frac{\xi+\theta}{1+\chi}\left(a_{t}+h_{t}\right) \\
m_{t} & =\chi \frac{c_{t}}{r_{t}+\pi_{t}},
\end{aligned}
$$

with variables without the $j$-index denoting aggregates. The evolution of aggregate human wealth follows $d h_{t}=\left(r_{t}+\xi\right) h_{t}-w_{t}+\tau_{t}-\Omega_{t}$. Aggregate non-human wealth is given by $a_{t}=k_{t}+b_{t}+m_{t}$ and follows the law of motion $d a_{t}=r_{t} a_{t}+w_{t}-(1+\chi) c_{t}+\Omega_{t}-\tau_{t}$. For further reference it is convenient to express the dynamics of the aggregate behavior of consumers in terms of $c_{t}$ and $a_{t}$. Upon differentiating $c_{t}$ with respect to time and substituting out for $h_{t}$, one obtains

$$
d c_{t}=\left(r_{t}-\theta\right) c_{t}-\xi \frac{\xi+\theta}{1+\chi} a_{t} .
$$

Equation (4) captures the well-known feature that, whenever $\xi>0$, the growth rate of individual consumption $\left(r_{t}-\theta\right)$ exceeds the growth rate of aggregate consumption, despite a constant propensity to consume out of wealth for all individuals. The reason for this is given by the fact that at any moment in time agents with a high level of non-human wealth are replaced by new-borns with zero non-human wealth. Because of this generational turnover effect aggregate consumption dynamics in the Euler equation (4) depend on the aggregate level of non-human wealth (which includes the outstanding level of government liabilities), in contrast to a standard Ramsey-economy with $\xi=0$. Of course, this is not the only way of introducing non-Ricardian behaviour in a macromodel. However, it has the advantage of introducing a pure wealth affect in consumption as the form of deviation from Ricardian equivalence, and moreover, this effect is entirely captured in a single parameter, $\xi$, thereby facilitating comparison with a Ricardian benchmark. Other relaxations of Ricardian equivalence, such as introducing credit constraints (Gali et al. (2004)) or distortionary taxation (Linnemann (2006)), will often be less tractable or contain direct supply side effects. Nevertheless, such devices are typically intended to have the effect of allowing fiscal policy (and the level of debt) to affect aggregate demand, such that our approach can be treated as a particularly tractable way of introducing such an effect and, if desired, can be calibrated to mimic the empirical evidence on the ability of fiscal policy to do this.

\subsection{Problems of the representative firms}

We have two types of firms in our model. 


\subsubsection{Capital rental firms}

There is a competitive continuum of firms which accumulate capital for rental to final goods producers. Let $i_{t}$ denote the real investment of these firms, using a mix of final goods which is identical to the private consumption pattern. Moreover, assume that capital depreciates at the rate $\delta>0$, leading to the law of motion for the capital stock

$$
d k_{t}=i_{t}-\delta k_{t}
$$

Capital rental firms are owned by private households. The return on capital is identical to the risk-free rate $r_{t}$ if the rental rate of capital $\left(p_{t}^{k}\right)$ charged to the final goods sector satisfies the zero-profit condition $p_{t}^{k}=r_{t}+\delta$.

\subsubsection{Final Goods Producers}

We assume that final goods are produced by imperfectly competitive firms which are subject to the constraints implied by Calvo-contracts (Calvo, 1983), such that at any point in time firms are able to change prices with instantaneous probability $\alpha$. Firms are lined up along the unit interval and a typical firm, with index $z$, produces according to a Cobb-Douglas function

$$
y(z)_{t}=n(z)_{t}^{\gamma} k(z)_{t}^{1-\gamma}
$$

Input markets are perfectly competitive. Cost-minimization implies that the combination of labour and capital employed by the firm is given by

$$
\frac{k(z)_{t}}{n(z)_{t}}=\frac{k_{t}}{n_{t}}=k_{t}=\frac{1-\gamma}{\gamma} \frac{w_{t}}{p_{t}^{k}}
$$

which is common across firms because of price-taking behavior in the input markets. Because of the Cobb-Douglas assumption, the cost function is linear in output, with marginal cost of production being given by

$$
M C_{t}=\left(p_{t}^{k}\right)^{1-\gamma} w_{t}^{\gamma} \gamma^{-\gamma}(1-\gamma)^{\gamma-1}
$$

In period $t$ firm $z$ is assumed to face the demand schedule

$$
y(z)_{t}=\left(\frac{p(z)_{t}}{p_{t}}\right)^{-\rho} y_{t}
$$

where $y_{t}$ is the total demand for final goods and $\rho>1$ denotes the constant elasticity of demand. ${ }^{9}$ The objective of a firm which has the chance to reset its price in period $t$ can be written as

$$
V_{t}=\int_{t}^{\infty}\left[\left(\frac{p(z)_{t}}{p_{s}}\right)^{1-\rho} y_{s}-M C_{s}\left(\frac{p(z)_{t}}{p_{s}}\right)^{-\rho} y_{s}\right] \cdot e^{-\int_{t}^{s}\left(r_{\mu}+\alpha\right) d \mu} d s .
$$

\footnotetext{
${ }^{9}$ The demand schedule is consistent with the Dixit-Stiglitz consumption aggregator $c_{t}=$ $\left[\int_{0}^{1} c(z)_{t}^{\frac{\rho-1}{\rho}} d z\right]^{\frac{\rho}{\rho-1}}$ and the aggregate price level $p_{t}=\left[\int_{0}^{1} p(z)_{t}^{1-\rho} d z\right]^{\frac{1}{1-\rho}}$. In line with these aggregators, it is assumed that investment and public consumption have the same demand structure as private consumption.
} 
The optimal price implied by the optimization of this objective function is given by

$$
p(z)_{t}=\frac{\int_{t}^{\infty} \rho\left(\frac{1}{p_{s}}\right)^{-\rho} M C_{s} y_{s} \cdot e^{-\int_{t}^{s}\left(r_{\mu}+\alpha\right) d \mu} d s}{\int_{t}^{\infty}(\rho-1)\left(\frac{1}{p_{s}}\right)^{1-\rho} y_{s} \cdot e^{-\int_{t}^{s}\left(r_{\mu}+\alpha\right) d \mu} d s}
$$

which represents the forward-looking generalization of the familiar static (or steady-state) mark-up pricing rule $p(z) / p=\rho /(\rho-1) M C$. The aggregate price index prevailing at time $t$ can be seen as a weighted average of prices set in the past, where the weights reflect the proportion of those prices that are still in existence, i.e.

$$
p_{t}=\left[\int_{-\infty}^{t} \alpha\left(p(z)_{s}\right)^{1-\rho} \cdot e^{-\alpha(t-s)} d s\right]^{\frac{1}{1-\rho}} .
$$

Finally, aggregate profits earned in the final goods sector can be written as

$$
\Omega_{t}=\int_{-\infty}^{t} \alpha\left[\left(\frac{p(z)_{s}}{p_{t}}\right)^{1-\rho}-M C_{t}\left(\frac{p(z)_{s}}{p_{t}}\right)^{-\rho}\right] y_{t} \cdot e^{-\alpha(t-s)} d s,
$$

with profits distributed to the private sector as specified in (2).

\subsection{The government}

Let $l_{t}$ denote aggregate real liabilities of the public sector, consisting of real balances and bonds, $l_{t}=m_{t}+b_{t}$. Substituting out for $m_{t}$, flow dynamics of public sector liabilities are given by

$$
d l_{t}=r_{t} l_{t}-\left(r_{t}+\pi_{t}\right) m_{t}+g-\tau_{t}=r_{t} l_{t}-\chi c_{t}+g-\tau_{t}
$$

where $g_{t}=g>0$ denotes an exogenous and constant stream of government expenditures in terms of aggregate final output. It is assumed that monetary and fiscal policies follow two stylized rules with a deliberately simple feedback structure. First, regarding monetary policy, we consider an inflation target of zero, i.e. $\pi=0$. Given the nominal stickiness due to Calvo-pricing contracts, the monetary agent has, in the short-run, leverage over the real interest rate and we consider a feedback rule of the form

$$
r_{t}=r+f^{M}\left(\pi_{t}-\pi\right), \quad \pi=0,
$$

where $r$ stands for the steady-state level of the real interest rate to be derived below. The single policy parameter $f^{M}$ in (7) is the Taylor-coefficient, as discussed in the literature on interest rate rules inspired by Taylor (1993). Accordingly, monetary policy is called 'active' ('passive') if the real interest rate $\left(r_{t}\right)$ rises (falls) in the current inflation rate, i.e. if $f^{M}>0\left(f^{M}<0\right)$. Since $(7)$ is directly expressed in terms of the real (and not the nominal) interest rate, the critical value of the Taylor-coefficient is zero (and not unity). Second, fiscal policy follows a feedback rule which aims at stabilizing government liabilities at some target level $l$. To achieve this target, lump-sum taxes get adjusted according to

$$
\tau_{t}=\tau+f^{F}\left(l_{t}-l\right) .
$$


With $g_{t}=g$ being fixed, the only fiscal instrument in (8) is $\tau_{t}$. This strong assumption serves to make departures from Ricardian equivalence in the local equilibrium analysis below as simple and transparent as possible. According to (6), in any steady-state equilibrium characterized by $\pi=0$ real government bonds are given by

$$
b=\frac{\tau-g}{r},
$$

implying that the real value of outstanding government bonds must be completely backed by the present value of future primary fiscal surpluses. There are two further comments worth making regarding the cashless limit to be considered below. First, as $\chi \rightarrow 0$, this implies $l_{t} \rightarrow b_{t}$, and the feedback rule (8) turns into a purely fiscal 'debt targeting rule'. Second, with real government debt growing at the real interest rate $r_{t}$, debt dynamics in (6) are, per se, locally not explosive if the single fiscal feedback parameter $f^{F}$ exceeds the steady-state interest rate $r$. Following the logic of Leeper (1991), we call the fiscal rule (8) 'passive' if $f^{F}>r$, while it is 'active' in the opposite and non-stabilizing case of $f^{F}<r .{ }^{10}$

\subsection{Summary of equilibrium conditions}

For further reference, the conditions which characterize dynamic equilibria at the aggregate level can be summarized as follows.

\section{Consumers:}

$$
d c_{t}=\left(r_{t}-\theta\right) c_{t}-\xi \frac{\xi+\theta}{1+\chi}\left(k_{t}+l_{t}\right)
$$

\section{Government:}

$$
\begin{aligned}
d l_{t} & =r_{t} l_{t}-\chi c_{t}+g-\tau_{t} \\
r_{t} & =r+f^{M} \pi_{t} \\
\tau_{t} & =\tau+f^{F}\left(l_{t}-l\right)
\end{aligned}
$$

Firms:

$$
\begin{aligned}
d k_{t} & =i_{t}-\delta k_{t} \\
y_{t} & =k_{t}^{1-\gamma} \\
k_{t} & =\frac{1-\gamma}{\gamma} \frac{w_{t}}{r_{t}+\delta} \\
M C_{t} & =\left(r_{t}+\delta\right)^{1-\gamma} w_{t}^{\gamma} \gamma^{-\gamma}(1-\gamma)^{\gamma-1} \\
p(z)_{t} & =\frac{\int_{t}^{\infty} \rho\left(\frac{1}{p_{s}}\right)^{-\rho} M C_{s} y_{s} \cdot e^{-\int_{t}^{s}\left(r_{\mu}+\alpha\right) d \mu} d s}{\int_{t}^{\infty}(\rho-1)\left(\frac{1}{p_{s}}\right)^{1-\rho} y_{s} \cdot e^{-\int_{t}^{s}\left(r_{\mu}+\alpha\right) d \mu} d s} \\
p_{t} & =\left[\int_{-\infty}^{t} \alpha\left(p(z)_{s}\right)^{1-\rho} \cdot e^{-\alpha(t-s)} d s\right]^{\frac{1}{1-\rho}}
\end{aligned}
$$

\footnotetext{
${ }^{10}$ The local equilibrium analysis carried out below is based on approximated laws of motions. For the analysis to be valid it is assumed that the two feedback parameters $f^{M}$ and $f^{F}$ are sufficiently close to the benchmark values of 0 and $r$, respectively.
} 


\section{Income identities:}

Mutual consistency of the plans of all consumers, firms, and the government requires that in equilibrium aggregate final output $y_{t}$ satisfies the market clearing condition

$$
y_{t}=c_{t}+g+i_{t} .
$$

In equilibrium, aggregate output must also satisfy the income identity

$$
y_{t}=w_{t}+\left(r_{t}+\delta\right) k_{t}+\Omega_{t},
$$

with aggregate profits $\Omega_{t}$ of the final goods sector defined as in equation (5). By the law of Walras, however, (20) and (21) are not independent. If (10)-(20) are satisfied, (21) will be satisfied as well if aggregate profits $\Omega_{t}$ follow (5). Because of the residual character of $\Omega_{t}$, we can drop (5) and (21) from the following analysis.

\section{Steady states}

\subsection{Existence}

To enhance the analytical tractability of the analysis we consider from now on the cashless limit $(\chi \rightarrow 0)$, implying $l_{t} \rightarrow b_{t}$. In steady state, $p(z)=p$, which we normalize to $p=1$. From (18), mark-up pricing implies $(\rho-1) / \rho=M C$. Combining (16)-(17), factor prices can be rewritten as a function of the capital stock

$$
\begin{aligned}
w & =\frac{\rho-1}{\rho} \gamma k^{1-\gamma}=w(k) \\
r & =\frac{\rho-1}{\rho}(1-\gamma) k^{-\gamma}-\delta=r(k),
\end{aligned}
$$

and $w(k)$ and $r(k)$ tend towards the marginal productivity expressions as the economy becomes perfectly competitive $(\rho \rightarrow \infty)$. Using $(23)$, the remaining equations can be arranged as a system in $c$ and $k$. Combining the steady-state version of the consumption Euler equation (10) with the government's budget constraint (11), yields

$$
c=\xi(\xi+\theta) \cdot \frac{k+\frac{\tau-g}{r(k)}}{r(k)-\theta},
$$

while the steady-state resource constraint is given by

$$
c=k^{1-\gamma}-\delta k-g .
$$

Equations (24) and (25) are similar to Blanchard (1985) and can be graphed as in Figure $1(a)$ to establish the differences between environments characterized by Ricardian and non-Ricardian consumers. In the Ricardian limit $(\xi=0)$, wealth effects with respect to asset holdings disappear and the economy has a unique steady state (with $k=k_{g r}$ ) 


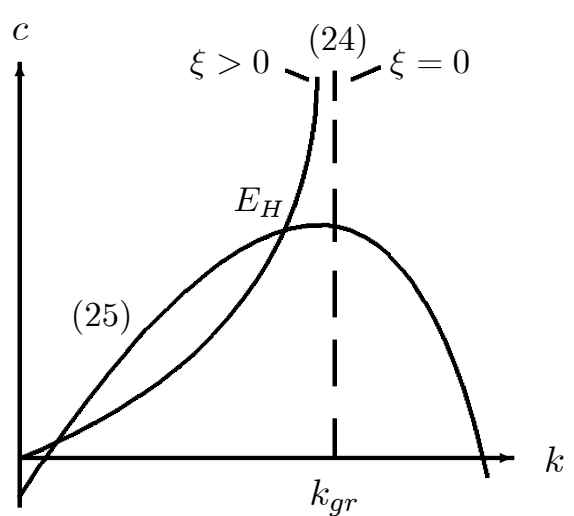

$(a)$

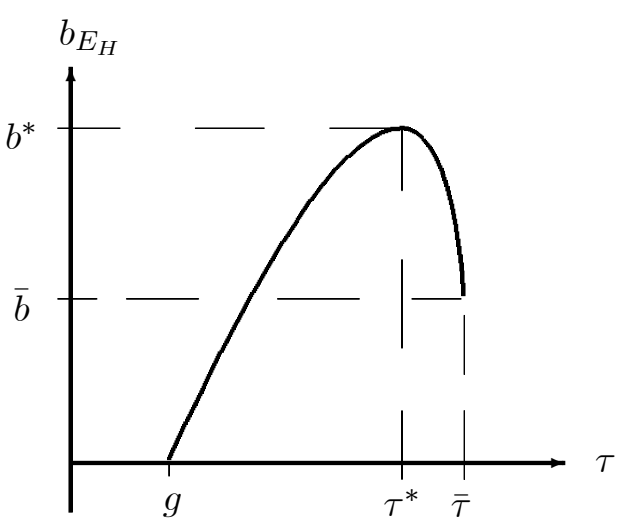

(b)

Figure 1: Steady-state configurations

which is characterized by the modified golden rule $r=\theta$, independently of the structure of debt and taxes. By contrast, if $\xi>0$ steady states exhibit $r>\theta$, since 'non-Ricardian' consumers are more impatient than infinitely lived 'Ricardian' consumers. To understand the non-Ricardian case in further detail, consider initially a situation of a balanced primary budget, i.e. $g=\tau \Leftrightarrow b=0$. Then, the economy is generically characterized by two steady states with positive levels of consumption, capital and output, as long as the level of government spending $g>0$ is not too large. Holding this level of $g$ constant, an increase in $\tau$ generates a positive level of government debt which at both steady states affects $k$ and $c$ via wealth effects. Intuitively, government bonds are perceived as net wealth by currently alive consumers, since the tax burden, backing these bonds, is partly borne by members of future generations. ${ }^{11}$ However, the amount of debt that can be passed on between different generations cannot be arbitrarily large. As $\tau$ keeps rising, (25) in Figure $1(a)$ remains unaffected, while (24) shifts upward, and there exists a unique value $\bar{\tau}(g)$, with associated debt level $\bar{b}$, beyond which the two steady states cease to exist.

We concentrate in the following exclusively on the high-activity steady state $\left(E_{H}\right)$ to facilitate a meaningful comparison of our results with the Ricardian benchmark. To find a simple operationalization for this, we make from now on the mild assumption

(A 1) $0<g<\gamma y$.

As shown in Appendix 1, under a balanced primary budget $(\tau=g)$ any steady state which satisfies (A 1) must be of the high-activity type. ${ }^{12}$ Importantly, as graphed in Figure 1(b),

\footnotetext{
${ }^{11}$ For further details, see, in particular, Weil (1991). The crucial mechanism for this result is not the probability of death, but rather the 'disconnectedness' between consumers currently alive and those born at some point in the future.

${ }^{12}$ Assumption (A 1) says that the government expenditure ratio should be less than the Cobb-Douglas co-
} 
at the high-activity steady state $\left(E_{H}\right)$ the relationship between $\tau$ and $b$ is non-monotonic if one increases $\tau$, holding $g$ constant. The intuition for this feature is as follows. As $\tau$ rises the primary surplus $\tau-g$ increases. Moreover, the real interest rate increases, since the wealth effect leads to a crowding out of physical capital. These two effects make the net effect on the steady-state debt level $b$, which is given by the discounted value of primary surpluses (i.e. $b=(\tau-g) / r)$ ), ambiguous. For $\tau$ sufficiently close to $g$ the first effect dominates and $b$ rises in $\tau$. However, there exists a unique value $\tau^{*}(g)$ which maximizes the steady-state value of government debt at $b^{*}$, while $b$ falls as $\tau$ further increases in the interval $\left(\tau^{*}, \bar{\tau}\right)$. For future reference, we summarize this pattern as follows:

Lemma 1 Consider a steady state of (24) and (25) with a balanced primary budget which satisfies $0<g=\tau<\gamma y$. Then, by varying $\tau$ and holding $g$ constant, there exists a range of efficient high-activity steady states $\left(E_{H}\right)$ characterized by $\tau \in\left(g, \tau^{*}\right) \Rightarrow b \in\left(0, b^{*}\right)$, and there exists a range of inefficient high-activity steady states $\left(E_{H}\right)$ characterized by $\tau \in\left(\tau^{*}, \bar{\tau}\right) \Rightarrow b \in\left(\bar{b}, b^{*}\right)$, as graphed in Figure $1(b)$.

Proof: See Appendix 1.

\subsection{Local dynamics}

Upon combining (10)-(20), local dynamics around steady states can be characterized by a dynamic system in $b_{t}, c_{t}, k_{t}$, and $\pi_{t}$. Given the non-linearity of the system, we consider a first-order approximation. Let $\widehat{x_{t}}=\frac{x_{t}-x}{x}, d \widehat{x_{t}}=\frac{\partial \widehat{x_{t}}}{\partial t}=\frac{\dot{x}_{t}}{x}$ for $x=b, c, k$. As regards inflation dynamics, since $\pi=0$, we consider $\pi_{t}$ and $d \pi_{t}=\dot{\pi}_{t}$, respectively.

Starting out from the differential equations (10), (11), and (14), when combined with the two feedback rules (12) and (13), it is straightforward to obtain the approximated laws of motion for $\widehat{b_{t}}, \widehat{c_{t}}$, and $\widehat{k_{t}}$ :

$$
\begin{aligned}
d \widehat{b b}_{t} & =\left(r-f^{F}\right) \widehat{b}_{t}+f^{M} \pi_{t} \\
d \widehat{c}_{t} & =-\xi(\xi+\theta) \frac{b}{c} \widehat{b}_{t}+(r-\theta) \widehat{c}_{t}-\xi(\xi+\theta) \frac{k}{c} \widehat{k}_{t}+f^{M} \pi_{t} \\
d \widehat{k}_{t} & =-\frac{c}{k} \widehat{c}_{t}+\left[(1-\gamma) \frac{y}{k}-\delta\right] \widehat{k}_{t} .
\end{aligned}
$$

Moreover, as derived in Appendix 2, inflation dynamics can be approximated by the expression:

$$
d \pi_{t}=-\alpha(r+\alpha) \gamma \widehat{k}_{t}+\left[r-\alpha(r+\alpha) \frac{f^{M}}{r+\delta}\right] \pi_{t}
$$

The equations (26)-(29) constitute a four-dimensional linear system of differential equations. The system is characterized by two state variables $\left(\widehat{b}_{t}, \widehat{k}_{t}\right)$ and two forward-looking jump variables $\left(\widehat{c}_{t}, \pi_{t}\right)$ with free initial conditions, and local dynamics can be assessed by

efficient of labour which is typically assumed to be around 2/3. Hence, (A 1) does not impose a 'restriction' that could become binding under plausible calibrations. 
the Blanchard-Kahn conditions. ${ }^{13}$ Let $J$ denote the Jacobian matrix of the system. Then,

$$
\begin{gathered}
{\left[\begin{array}{c}
d \widehat{b}_{t} \\
d \widehat{c}_{t} \\
d \widehat{k}_{t} \\
d \pi_{t}
\end{array}\right]=J \cdot\left[\begin{array}{c}
\widehat{b}_{t} \\
\widehat{c}_{t} \\
\widehat{k}_{t} \\
\pi_{t}
\end{array}\right], \quad \text { with: }} \\
J=\left[\begin{array}{cccc}
r-f^{F} & 0 & 0 & f^{M} \\
-\xi(\xi+\theta) \frac{b}{c} & r-\theta & -\xi(\xi+\theta) \frac{k}{c} & f^{M} \\
0 & -\frac{c}{k} & (1-\gamma) \frac{y}{k}-\delta & 0 \\
0 & 0 & -\alpha(r+\alpha) \gamma & r-\alpha(r+\alpha) \frac{f^{M}}{r+\delta}
\end{array}\right]
\end{gathered}
$$

\section{Classification of local equilibrium dynamics}

The next two sections address in turn the implications of (30) for the classification of local equilibrium dynamics under Ricardian and non-Ricardian consumers, respectively.

\subsection{Ricardian consumers $(\xi=0)$}

As discussed, steady states with Ricardian consumers $(\xi=0)$ are characterized by the modified golden rule, $r=\theta$. Hence, the matrix $J$ in (30) turns into

$$
J=\left[\begin{array}{cccc}
\theta-f^{F} & 0 & 0 & f^{M} \\
0 & 0 & 0 & f^{M} \\
0 & -\frac{c}{k} & (1-\gamma) \frac{y}{k}-\delta & 0 \\
0 & 0 & -\alpha(\theta+\alpha) \gamma & \theta-\alpha(\theta+\alpha) \frac{f^{M}}{\theta+\delta}
\end{array}\right]
$$

Compared with (30), the assumption of $\xi=0$ simplifies the dynamic structure of the economy in two important ways, both linked to the aggregate consumption Euler equation as described by the second row in (31). First, since government bonds are not perceived as net wealth, consumption dynamics are not affected by government debt dynamics, $\xi(\xi+\theta) \frac{b}{c}=0$. In fact, government debt dynamics do not affect any of the other three dynamic equations. As a result of this separability, one eigenvalue of (31) is given by $\lambda=\theta-f^{F}$. Second, the absence of wealth effects also implies that consumption dynamics are not affected by capital dynamics, $\xi(\xi+\theta) \frac{k}{c}=0$. This leads to a well-known and simple relationship between the stance of monetary policy (measured by $f^{M}$ ) and the profile of consumption close to the steady state, reflecting the assumption of logarithmic utility in consumption. This relationship says that if in response to some shock inflation is above target $\left(\pi_{t}>0\right)$ consumption slopes upward (downward), whenever monetary policy is active (passive), while it stays flat if monetary policy is neutral $\left(f^{M}=0\right)$.

Exploiting the separability of government debt dynamics, we address first the isolated monetary dynamics before we then turn to the joint monetary and fiscal dynamics of (31).

\footnotetext{
${ }^{13}$ The notion of a predetermined stock of real government debt can be justified as follows. First, because a fraction of firms sets prices in a forwardlooking manner, the inflation rate $\pi_{t}$ is a jump variable. Second, assume that the stock of nominal government bonds is predetermined. Then, real government debt must be counted as a state variable, because it cannot move independently of the jump in inflation.
} 


\subsubsection{Monetary dynamics}

By deleting the first column and the first row in (31), monetary dynamics can be readily inferred from the remaining sub-system in $c, k$, and $\pi$. The monetary sub-system is characterized by one state variable $(k)$ and two forward-looking variables $(c, \pi)$.

\section{Proposition 1 Monetary dynamics}

Consider the dynamic sub-system in $c, k, \pi$ implied by the matrix (31).

1) Assume monetary policy is passive. Then, dynamics are always determinate.

2) Assume monetary policy is active. Then, dynamics are never determinate. There exists a critical value $q>0$ such that dynamics are indeterminate of degree 1 if $f^{M}>q$.

Proof: With one state variable and two forward-looking variables, dynamics are determinate if $J^{c, k, \pi}$ has one negative and two positive eigenvalues. ${ }^{14}$ Let

$$
\begin{aligned}
\operatorname{Det}\left(J^{c, k, \pi}\right) & =\frac{c}{k} \alpha(\theta+\alpha) \gamma f^{M}, \\
\operatorname{Tr}\left(J^{c, k, \pi}\right) & =(1-\gamma) \frac{y}{k}-\delta+\theta-\alpha(\theta+\alpha) \frac{f^{M}}{\theta+\delta}
\end{aligned}
$$

denote the determinant and the trace of the $3 x 3$-matrix $J^{c, k, \pi}$, respectively. Assume $f^{M}<0$. Then, $\operatorname{Det}\left(J^{c, k, \pi}\right)<0$ and $\operatorname{Tr}\left(J^{c, k, \pi}\right)>0$, implying one negative and two positive eigenvalues. Assume $f^{M}>0$. Then, $\operatorname{Det}\left(J^{c, k, \pi}\right)>0$, i.e. dynamics are never determinate. Note that $\operatorname{Tr}\left(J^{c, k, \pi}\right)$ is a linear function of $f^{M}$, and $\operatorname{Tr}\left(J^{c, k, \pi}\right)<0$ obtains if $f^{M}$ becomes sufficiently large. Hence, there exists a critical value $q$ such that $J^{c, k, \pi}$ has two negative and one positive eigenvalues, implying dynamics are indeterminate of degree 1 if $f^{M}>q$.

Proposition 1 reflects the fact that local stability types of steady states under monetary dynamics depend on the single feedback parameter $f^{M}$. The critical value $f^{M}=0$ defines the boundary value for the unique parameter region of determinacy. ${ }^{15}$ It is worth pointing out that in the New Keynesian version of the model of Blanchard (1985), as developed in this paper, passive (and not active) monetary policy is a necessary and sufficient condition for determinate dynamics. Since the model is in many ways standard, the failure of the Taylor-principle may seem surprising, but there are two non-standard elements. First, labour supply is assumed to be fixed. Second, monetary policy has non-trivial supply-side effects because of the contemporaneous link between the real interest rate and the return on physical capital, as recently discussed in Dupor (2001) and Carlstrom and Fuerst (2005). We show below that the failure of the Taylor-principle is entirely due to the second aspect. More specifically, we show, at the expense of more tedious algebra, that the classification of Proposition 1 remains unaffected if one augments preferences with a standard elastic or even linear labour supply specification. However, since the Taylor principle itself is

\footnotetext{
${ }^{14}$ We do not distinguish explicitly between real and conjugate complex eigenvalues, i.e. our classification refers to the real part of any eigenvalue which is crucial for the stability behaviour.

${ }^{15}$ For small positive values of $f^{M}$ one obtains $\operatorname{Det}\left(J^{c, k, \pi}\right)>0$ and $\operatorname{Tr}\left(J^{c, k, \pi}\right)>0$ such that $f^{M}=0$ separates a region of determinacy from a region of instability (i.e. all three eigenvalues are positive).
} 
qualitatively not important for the main results of this paper, given our focus on the dependence of the nature of local dynamics on the target level of government debt, we delegate this discussion to a self-contained analysis in Section 5.

\subsubsection{Monetary and fiscal dynamics}

Under Ricardian consumers it is straightforward to extend any clear-cut characterization of the monetary sub-dynamics, as summarized in Proposition 1, to a characterization of the combined monetary and fiscal dynamics. Fiscal policy adds a second state variable (b) and an additional eigenvalue $\lambda=\theta-f^{F}$. This eigenvalue is negative (positive) if fiscal policy is passive (active). Combining this pattern with Proposition 1, one obtains:

\section{Proposition 2 Monetary and fiscal dynamics}

Consider the dynamic system in $b, c, k, \pi$ implied by the matrix (31).

1) Assume monetary and fiscal policy are passive. Then, dynamics are always determinate.

2) Assume monetary and fiscal policy are active. Then, dynamics are determinate if $f^{M}>q$, with $q$ as established in Proposition 1.

3) Assume monetary policy is passive and fiscal policy is active or, alternatively, monetary policy is active and fiscal policy is passive. Then, dynamics are never determinate.

Proposition 2 summarizes that fiscal policy contributes to the local stability properties of steady states in a rather mechanical way if consumers are Ricardian. Essentially, whenever the monetary sub-dynamics by themselves are determinate, this feature will be preserved if fiscal policy behaves passively, i.e. if government debt dynamics evolve in a self-stabilizing manner. By contrast, active fiscal policy is decisive for the achievement of determinate dynamics whenever the monetary sub-dynamics exhibit one degree of indeterminacy. Intuitively, in this situation active fiscal policy ensures that arbitrary expectations of inflation can no longer be validated in equilibrium since the local stability requirement of government debt imposes uniquely defined values for the forward-looking variables $(c, \pi)$. This same mechanism is also at the heart of the 'fiscal theory of the price level', as developed by Woodford (1994) and Sims (1994).

For future reference, Figure 2 illustrates how the assumption of Ricardian consumers reduces the joint design problem of monetary and fiscal policy-making to two separable problems which can be recursively addressed. Shaded areas describe the parameter regions of determinacy established in Proposition 2. These regions are separated by the demarcation line of active vs. passive fiscal policy-making $\left(f^{F}=\theta\right)$ and they are independent of the target level of government debt. Again, we point out that this qualitative result does in no way depend on the failure of the Taylor-principle in Section 4.1.1 on monetary dynamics. Similarly, a richer monetary feedback-rule (reacting, for example, also to some measure of real economic activity along the lines of Woodford (2003)), leading to a critical value different from $f^{M}=0$, can be accommodated with the same logic, as long as government debt dynamics remain separable. 


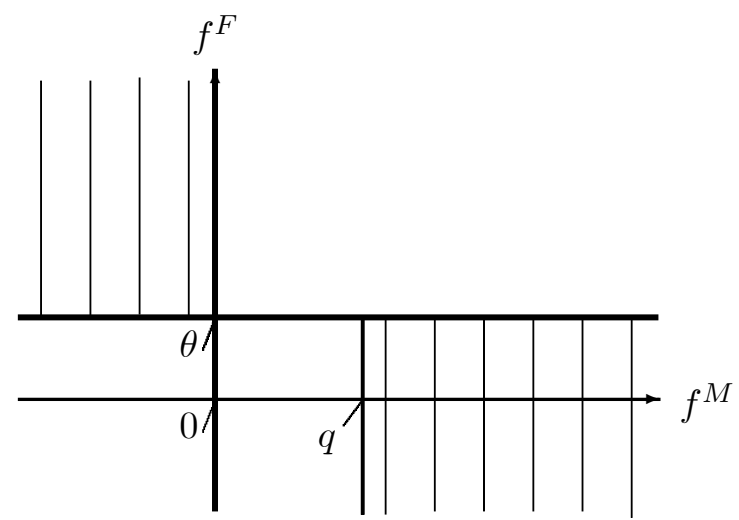

Shaded areas: Regions of local determinacy

Figure 2: Monetary and fiscal dynamics: Ricardian consumers

\subsection{Non-Ricardian consumers $(\xi>0)$}

Owing to the non-Ricardian structure, consumption dynamics are now, in general, affected by the dynamics of government debt, implying that the transition matrix $J$ in (30) is no longer separable with respect to fiscal policy. Reflecting the non-neutral role of fiscal policy, the entries of $J$ in (30) depend crucially on the 'position' of the high-activity steady state $\left(E_{H}\right)$ which itself depends on fiscal policy. In particular, for any given level of $g$, the levels of $c, k$ and $r$ depend on the steady-state mix between bonds and taxes in a non-trivial manner, as summarized in Lemma 1.

To assess the implications of the non-Ricardian structure for the local dynamics of steady states it is instructive, in a first step, to investigate the necessary condition for determinacy

$$
\operatorname{Det}(J)=\left[r-f^{F}\right]\left[\sigma_{0}+\sigma_{1} f^{M}\right]+r \sigma_{2} f^{M}>0
$$

where the coefficients $\sigma_{0}, \sigma_{1}$, and $\sigma_{2}$ are functions of the fiscal parameters. Notice that all technical results used from now onwards in this Subsection are summarized in Appendix 3. Rearranging (34) one obtains for the critical demarcation line $\operatorname{Det}(J)=0$ the expression

$$
\operatorname{Det}(J)=0 \Leftrightarrow f^{F}=r\left(1+\frac{\sigma_{2} f^{M}}{\sigma_{0}+\sigma_{1} f^{M}}\right) .
$$

\subsubsection{Efficient steady states}

Assume first that steady states are efficient, implying that there is for a given level of $g$ a one-to-one relationship between taxes and debt, i.e. $g<\tau<\tau^{*} \Rightarrow 0<b<b^{*}$. Then, depending on the target level of debt, $\operatorname{Det}(J)=0$ has two distinct configurations in $f^{M}-f^{F}-$ space which can be graphed as in Figures $3(a)$ and $(b)$. To relate these two graphs to the previous discussion notice that if $\xi=0$ the locus of $\operatorname{Det}(J)=0$ coincides, 


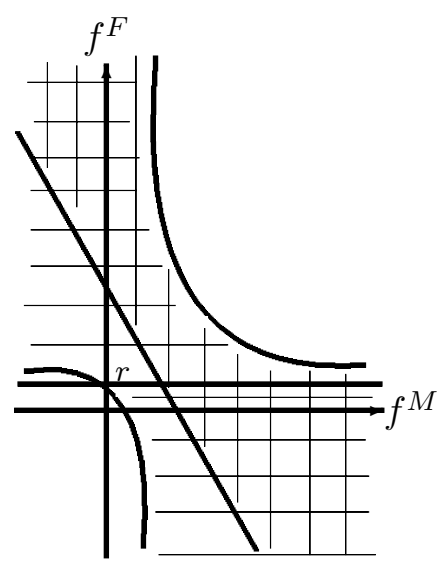

(a) $\tau \in\left(g, \tau_{1}\right)$

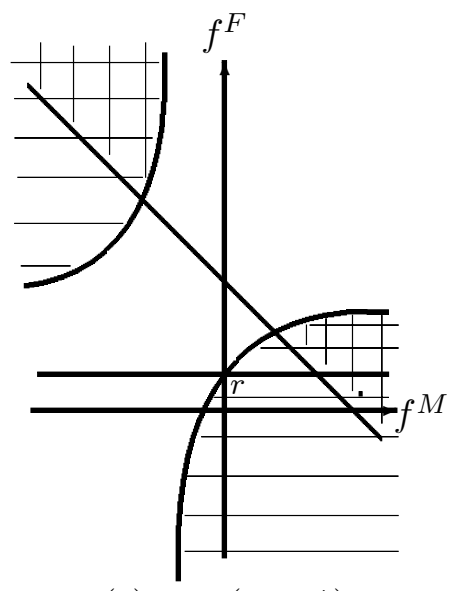

(b) $\tau \in\left(\tau_{1}, \tau^{*}\right)$

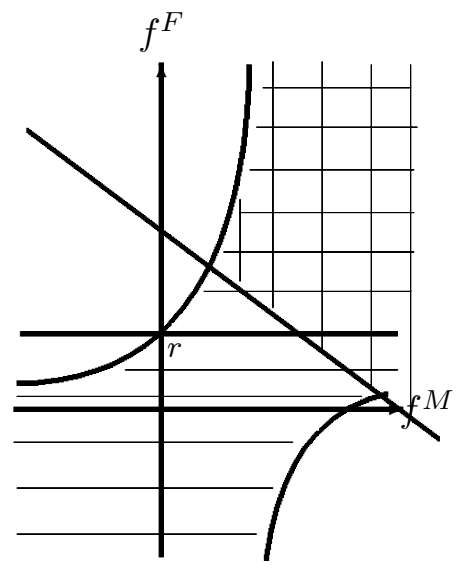

(c) $\tau \in\left(\tau^{*}, \bar{\tau}\right)$

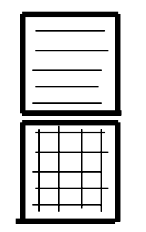

$\operatorname{Det}(J)>0$ : Necessary condition for local determinacy

$\operatorname{Det}(J)>0, \operatorname{Tr}(J)<0$ : Sufficient condition for local determinacy

Figure 3: Monetary and fiscal dynamics: non-Ricardian consumers

irrespective of the level of debt, in both cases with the demarcation lines of active vs. passive policy-making (i.e. $f^{F}=r$ and $f^{M}=0$ ), as graphed in Figure 2. If $\xi>0$, however, there exist two distinct regimes. Intuitively, for small levels of debt the wealth effect is also small and the parameter region consistent with $\operatorname{Det}(J)>0$ is close to the combinations of active and passive policy-making underlying Figure $2 .{ }^{16}$ As $b$ rises the wealth effect becomes relatively more important, leading to changes in the steady state levels of $c, k, r$ and, hence, also in $\sigma_{0}, \sigma_{1}$, and $\sigma_{2}$. We show that there exist unique threshold values $\tau_{1} \in\left(g, \tau^{*}\right) \Rightarrow b_{1} \in\left(0, b^{*}\right)$ which lead to a change in the sign pattern of $\sigma_{0}, \sigma_{1}$, and $\sigma_{2}$. This change implies that at the target level of government debt $b_{1}$ the locus associated with $\operatorname{Det}(J)=0$ switches from Figure 3(a) to Figure 3(b), leading to a qualitative change of the local dynamics of the system. Intuitively, there is scope for the existence of such threshold values because of the endogeneity of the capital stock. This feature ensures that the wealth effect of government debt affects not only the demand side, but also the supply-side of the system, since any change in the real interest rate resulting from crowding out effects shifts the marginal cost schedule of firms. Figures 3(a) and $(b)$ reveal that this interaction is very non-linear. In particular, the two regimes, as graphed in Figures 3(a) and 3(b), have the feature that there always exist regions of the parameter space which are necessary for locally determinate dynamics at 'low debt' steady states,

\footnotetext{
${ }^{16}$ Specifically, assuming non-Ricardian consumers, it is easy to check within (30) that in the special caseof of $b=0$ one eigenvalue of $J$ is given by $r-f^{F}$. Hence, $f^{F}=r \operatorname{implies} \operatorname{Det}(J)=0$, similar to Figure 2. However, if $b=0$ there are nevertheless wealth effects associated with the capital stock. Because of this feature, $f^{M}=0$ no longer implies $\operatorname{Det}(J)=0$.
} 
but not at 'high debt' steady states, and vice versa.

The reasoning so far is based on a necessary condition. To make it more operational we combine (34) with the additional trace-condition $\operatorname{Tr}(J)<0$. It can be established that

$$
\operatorname{Det}(J)>0, \operatorname{Tr}(J)<0
$$

is a sufficient condition for locally determinate dynamics. ${ }^{17}$ From (30), the trace of $J$ is given by

$$
\begin{aligned}
\operatorname{Tr}(J) & =\omega_{0}-f^{F}-\omega_{1} \cdot f^{M}, \text { with: } \\
\omega_{0} & =3 r-\theta+(1-\gamma) \frac{y}{k}-\delta>0, \quad \omega_{1}=\frac{\alpha(r+\alpha)}{r+\delta}>0,
\end{aligned}
$$

which can be rearranged as

$$
\operatorname{Tr}(J)=0 \Leftrightarrow f^{F}=\omega_{0}-\omega_{1} \cdot f^{M} .
$$

Equation (37) describes at all debt levels a straight line with positive intercept and negative slope in $f^{M}-f^{F}$ - space, leading to the graphical representation of the sufficiencycondition given in Figure 3. In sum, this leads to the conclusion:

Proposition 3 Monetary and fiscal dynamics at efficient steady states

Assume $\tau \in\left(g, \tau^{*}\right) \Rightarrow b \in\left(0, b^{*}\right)$.

1) Reflecting the non-neutral role of fiscal policy, determinacy regions depend on the steadystate level of debt and they are no longer separated by the demarcation lines of active and passive fiscal policy-making.

2) There exist two qualitatively distinct regimes of local equilibrium dynamics, characterized by low steady-state debt (i.e. $\left.\tau \in\left(g, \tau_{1}\right) \Rightarrow b \in\left(0, b_{1}\right)\right)$ and high steady-state debt (i.e. $\left.\tau \in\left(\tau_{1}, \tau^{*}\right) \Rightarrow b \in\left(b_{1}, b^{*}\right)\right)$. These two regimes have the feature that there always exist regions of the parameter space which ensure locally determinate dynamics at 'low debt' steady states, but not at 'high debt' steady states, and vice versa, as graphed in Figures $3(a)$ and $3(b)$.

The first part of Proposition 3 summarizes the obvious insight that the assumption of nonRicardian consumers leads to a genuine interaction between monetary and fiscal policy. This interaction implies that determinate dynamics require appropriate degrees of activism and passivism within either rule, and these degrees need to be jointly established. The second part of Proposition 3, however, is a priori not obvious, because it says that the level of government debt affects the interaction between monetary and fiscal stabilization policies in a highly non-linear way. In other words, if fiscal policy is non-neutral, meaningful characterizations of monetary and fiscal stabilization policies are conditional on the prevailing regime with respect to the target level of government debt. If this dependence is

\footnotetext{
${ }^{17}$ To further clarify the differences between Figures 2 and 3, notice that the shaded areas in Figure 2 are based on a condition which is necessary and sufficient for local determinacy. By contrast, in Figure 3 horizontally shaded areas correspond to a necessary condition, while horizontally and vertically shaded areas correspond to a sufficient condition.
} 
not made explicit (and policies are solely characterized in terms of the feedback parameters $f^{F}$ and $f^{M}$ ), policy recommendations may well be misleading.

To illustrate this general principle, consider, for the sake of exposition, a combination of active monetary and passive fiscal policy-making. Under Ricardian consumers, this is never consistent with determinate dynamics, reflecting the failure of the Taylor-principle in Section 3 in the isolated monetary sub-dynamics. However, under non-Ricardian consumers there always exist certain combinations of active monetary and passive fiscal policy-making consistent with determinate dynamics. In other words, conditional on an appropriate specification of the passivism of fiscal policy, the Taylor principle reappears for certain degrees of active monetary policy. Yet, depending on whether the steady state is characterized by low or high debt, these combinations show significant differences.

Corollary 1 Active monetary and passive fiscal policy at efficient steady states 1) Consider steady states with low debt, i.e. $0<b<b_{1}$. Then, if monetary policy becomes more active, the fiscal discipline consistent with determinate dynamics decreases.

2) Consider steady states with high debt, i.e. $b_{1}<b<b^{*}$. Then, if monetary policy becomes more active, the fiscal discipline consistent with determinate dynamics increases, but remains bounded from above.

\subsubsection{Inefficient steady states}

For completeness, we extend the analysis to inefficient steady states, i.e. in terms of Figure $1(b)$ we focus on inefficiently high tax rates $\tau \in\left(\tau^{*}, \bar{\tau}\right)$ which are associated with debt levels $b \in\left(\bar{b}, b^{*}\right)$. Under this assumption, there emerges a third region of the parameter space with distinct equilibrium dynamics, as illustrated in Figure 3(c).

Proposition 4 Monetary and fiscal dynamics at inefficient steady states Assume $\tau \in\left(\tau^{*}, \bar{\tau}\right) \Rightarrow b \in\left(\bar{b}, b^{*}\right)$. Then, the non-neutrality features of Proposition 3 extend to a third regime with qualitatively distinct local equilibrium dynamics, as graphed in Figure $3(c)$.

Proposition 4 extends Proposition 3 in a straightforward manner. Essentially, it says that if the relationship between taxes and debt becomes non-monotonic (in line with the logic of Laffer curves) the target level of debt no longer summarizes all the relevant information on which characterizations of stabilization policies should be conditioned. Instead, the target levels of both taxes and debt need to be made explicit.

Not surprisingly, if non-Ricardian consumers face both high debt and inefficiently high taxes this leads to local equilibrium dynamics which differ from the benchmark case of Ricardian consumers in the strongest possible way, as shown in Figure 3(c). To summarize the characteristics of this third regime, it is instructive to focus again on combinations of active monetary and passive fiscal policy-making. 
Corollary 2 Active monetary and passive fiscal policy at inefficient steady states Consider inefficient steady states, i.e. $\tau \in\left(\tau^{*}, \bar{\tau}\right) \Rightarrow b \in\left(\bar{b}, b^{*}\right)$. Then, if monetary policy becomes more active, the fiscal discipline consistent with determinate dynamics increases without bound. ${ }^{18}$

Remark: All technical results stated in Section 4.2 are derived in Appendix 3.

\section{Endogenous labour supply of Ricardian consumers}

This self-contained section has the purpose to identify the mechanism which leads to the failure of the Taylor-principle under Ricardian consumers $(\xi=0)$, as established in Proposition 1. Specifically, the Section shows that this failure is not caused by the assumption of a fixed labour supply which this paper has borrowed from the original contribution of Blanchard (1985). ${ }^{19}$ Instead, the failure of the Taylor principle is due to the contemporaneous link between the real interest rate and the return on physical capital in continuous time models, in line with the careful discussions in Dupor (2001) and Carlstrom and Fuerst (2005). ${ }^{20}$ Moreover, if being sufficiently aggressive $\left(f^{M}>q\right)$ active monetary policy is consistent with non-fundamental fluctuations in activity, resulting from local indeterminacy of degree 1 . The intuition for such non-fundamental fluctuations may be summarized as follows. Assume first that the labour supply is fixed. Moreover, assume that inflation is expected to be above target, triggering an expected rise in the real interest rate under active monetary policy. Via arbitrage this implies that the rental rate on capital needs to rise as well. This in turn requires, for a predetermined level of the capital stock and a fixed labour supply, a lower mark-up charged in the final goods sector. This channel is on impact expansionary, and the associated rise in actual inflation may well become self-fulfilling under a consumption profile that follows on impact a rising path (supported by an increase in investment and output), before gradually returning to the initial steady state. $^{21}$ By contrast, if monetary policy is passive, such self-fulfilling expectations can never be validated, leading to locally determinate dynamics.

The assumption of an elastic labour supply reinforces this logic since self-fulfilling increases in the inflation rate and the real interest rate under active monetary policy can now be supported through a second margin, namely an increase in the labour supply. To substantiate this claim, we replace (1) by the more general utility function

$$
E_{t} U^{j}=\int_{t}^{\infty}\left[\ln c_{s}^{j}+\frac{1}{1-\psi}\left(1-n_{s}^{j}\right)^{1-\psi}+\chi \ln m_{s}^{j}\right] \cdot e^{-\theta(s-t)} d s
$$

\footnotetext{
${ }^{18}$ This statement is subject to the caveat expressed in Footnote 10.

${ }^{19}$ There is a separate discussion in the literature of how to equip non-Ricardian consumers $(\xi>0)$ with an endogenous labour supply, as discussed, in particular, by Ascari and Rankin (2004). Since we go in the main part of the analysis with the model of Blanchard (1985), this discussion does not affect our paper.

${ }^{20}$ Alternative mechanisms challenging the logic of the Taylor principle are discussed, among others, in Benhabib et al. (2001a), Carlstrom and Fuerst (2001), and Gali et al. (2004).

${ }^{21}$ The fact that a self-fulfilling burst in inflation comes together with an increase in the real interest rate may be intuitively classified as a dominance of supply-side over demand-side effects. However, any equilibrium sequence must always be consistent with both the demand side and the supply side of the economy.
} 
where $n_{s}^{j} \in(0,1)$ denotes the flexible level of individual labour supply and $\psi>0$ denotes the coefficient of relative risk aversion to variations in leisure. Accordingly, individual labour supply satisfies the first-order condition $n_{s}^{j}=1-\left(c_{s}^{j} / w_{s}\right)^{1 / \psi}$. Compared with the previously derived set of aggregate equilibrium conditions (10)-(20), the assumption of (38) leads to three straightforward modifications, on top of imposing $\xi=0$. First, the aggregate labour-supply relationship

$$
n_{t}=1-\left(\frac{c_{t}}{w_{t}}\right)^{\frac{1}{\psi}}
$$

acts as an additional equilibrium condition in order to pin down $n_{t} \in(0,1)$. Moreover, the two conditions

$$
y_{t}=n_{t}^{\gamma} k_{t}^{1-\gamma}
$$

and

$$
\frac{k_{t}}{n_{t}}=\frac{1-\gamma}{\gamma} \frac{w_{t}}{r_{t}+\delta}
$$

replace (15) and (16), respectively. ${ }^{22}$ Similar to the analysis in Section 4.1, the new set of aggregate equilibrium conditions gives rise to a unique steady state which is characterized by the modified golden rule $r(k / n)=\theta$, as summarized in Appendix 4. For the sake of a compact notation, let

$$
\varepsilon=\psi \frac{n}{1-n}>0
$$

denote the inverse of the Frisch elasticity of the labour supply with respect to the real wage. Then, as derived in Appendix 4, local dynamics around the unique steady state are approximately given by

$$
\begin{aligned}
& {\left[\begin{array}{c}
\widehat{d b}_{t} \\
d \widehat{c}_{t} \\
d \widehat{k}_{t} \\
d \pi_{t}
\end{array}\right]=J \cdot\left[\begin{array}{c}
\widehat{b}_{t} \\
\widehat{c}_{t} \\
\widehat{k}_{t} \\
\pi_{t}
\end{array}\right], \quad \text { with: }} \\
& J=\left[\begin{array}{cccc}
\theta-f^{F} & 0 & 0 & f^{M} \\
0 & 0 & 0 & f^{M} \\
0 & -\left[\gamma \frac{1}{1+\varepsilon} \frac{y}{k}+\frac{c}{k}\right] & \gamma \frac{1}{1+\varepsilon} \frac{y}{k}+(1-\gamma) \frac{y}{k}-\delta & \gamma \frac{1}{1+\varepsilon} \frac{y}{k} \frac{f^{M}}{\theta+\delta} \\
0 & -\alpha(\theta+\alpha) \gamma \frac{1}{1+\varepsilon} & -\alpha(\theta+\alpha) \gamma \frac{\varepsilon}{1+\varepsilon} & \theta-\alpha(\theta+\alpha)\left[1-\gamma \frac{1}{1+\varepsilon}\right] \frac{f^{M}}{\theta+\delta}
\end{array}\right],
\end{aligned}
$$

i.e. the transition matrix $J$ in (42) generalizes the previously discussed matrix (31) by allowing for an elastic labour supply. ${ }^{23}$ Consider the monetary dynamics of $(42)$ in $c, k$, and $\pi$. Then, $\operatorname{Det}\left(J^{c, k, \pi}\right)$ and $\operatorname{Tr}\left(J^{c, k, \pi}\right)$ are given by $\operatorname{Det}\left(J^{c, k, \pi}\right)=\eta_{1} f^{M}$ and $\operatorname{Tr}\left(J^{c, k, \pi}\right)=$ $\eta_{2}-\eta_{3} f^{M}$, with:

$$
\begin{aligned}
\eta_{1} & =\left[\gamma \frac{1}{1+\varepsilon} \frac{y}{k}+\frac{c}{k}\right]\left[\alpha(\theta+\alpha) \gamma \frac{\varepsilon}{1+\varepsilon}\right]+\left[\gamma \frac{1}{1+\varepsilon} \frac{y}{k}+(1-\gamma) \frac{y}{k}-\delta\right]\left[\alpha(\theta+\alpha) \gamma \frac{1}{1+\varepsilon}\right]>0 \\
\eta_{2} & =\gamma \frac{1}{1+\varepsilon} \frac{y}{k}+(1-\gamma) \frac{y}{k}-\delta+\theta>0, \quad \eta_{3}=\alpha(\theta+\alpha)\left[1-\gamma \frac{1}{1+\varepsilon}\right]>0 .
\end{aligned}
$$

\footnotetext{
${ }^{22}$ Moreover, (21) generalizes to $y_{t}=w_{t} n_{t}+\left(r_{t}+\delta\right) k_{t}+\Omega_{t}$, without affecting, however, the residual role of this identity.

${ }^{23}$ To see the link between the two matrices, notice that as $\psi \rightarrow \infty$ the labour supply becomes fully inelastic (i.e. 'fixed'). Correspondingly, $\frac{1}{1+\varepsilon} \rightarrow 0$ and $\frac{\varepsilon}{1+\varepsilon} \rightarrow 1$, and (42) converges against (31).
} 
The sign pattern of the coefficients $\eta_{1}, \eta_{2}$, and $\eta_{3}$ is the same as in (32) and (33). This implies that Propositions 1 and 2 remain unchanged if preferences allow for an elastic labour supply. ${ }^{24}$

Finally, to link the analysis of this Section explicitly to Dupor (2001), consider the particularly tractable case of a linear labour supply, as given by $\psi \rightarrow 0$. Then, since $\frac{1}{1+\varepsilon} \rightarrow 1$ and $\frac{\varepsilon}{1+\varepsilon} \rightarrow 0$, the structure of (42) further simplifies. Specifically, the transition matrix $J^{c, k, \pi}$ converges against

$$
J^{c, k, \pi}=\left[\begin{array}{ccc}
0 & 0 & f^{M} \\
-\left[\gamma \frac{y}{k}+\frac{c}{k}\right] & \frac{y}{k}-\delta & \gamma \frac{y}{k} \frac{f^{M}}{\theta+\delta} \\
-\alpha(\theta+\alpha) \gamma & 0 & \theta-\alpha(\theta+\alpha)[1-\gamma] \frac{f^{M}}{\theta+\delta}
\end{array}\right],
$$

and the sign pattern of all entries of (43) is identical to the matrix investigated in detail by Dupor (2001, p. 92). Since the dynamics of $c$ and $\pi$ are independent of the capital stock dynamics, one eigenvalue of the $3 x 3$-dynamics can be directly read off from (43), i.e. $\lambda=\frac{y}{k}-\delta>0 .{ }^{25}$ Exploiting this special feature, Dupor offers a particularly transparent discussion of why the Taylor principle has no bite if there exists a contemporaneous link between the real interest rate and the return on physical capital in continuous time models. ${ }^{26}$

However, the failure of the Taylor principle in models with capital stock dynamics is not a generic feature of discrete time models, as shown by Carlstrom and Fuerst (2005). ${ }^{27}$ Intuitively, discrete time models allow for a natural distinction between the marginal productivity of 'today' and of the 'future'. If one relates the real interest rate to the future marginal productivity of capital this essentially removes the binding restriction on the return rates which causes the failure of the Taylor principle in continuous time. ${ }^{28}$ It is for this reason that we emphasized early on that our paper does not give new insights on the role of the Taylor principle per se. However, our result that the nature of local determinacy requirements varies with the target level of government debt is likely to be a robust result in models which include capital and non-Ricardian consumers even if we

\footnotetext{
${ }^{24}$ Numerically, the critical value $q$ will be different, but this does not affect the nature of Propositions 1 and 2 .

${ }^{25}$ Dupor introduces nominal rigidities through utility-based price adjustment costs, while this paper uses Calvo contracts. This difference, however, does not affect the qualitative reduced-form feature of separable capital stock dynamics under a linear labour supply.

${ }^{26}$ Related to this, see also the discussion of the Taylor principle after Proposition 6 in Benhabib et al. (2001b). In particular, the paper points out that the Taylor principle becomes fragile if the sign of the derivative of $d \pi$ with respect to $\pi$ is ambiguous because of feedbacks between the nominal interest rate and production. Notice that in our paper this derivate is given by the term $\theta-\alpha(\theta+\alpha)\left[1-\gamma \frac{1}{1+\varepsilon}\right] \frac{f^{M}}{\theta+\delta}$, and the ambiguity of the sign of this term arises because changes in the interest rate (in response to inflation changes) affect marginal costs of firms.

${ }^{27}$ Similarly, see Li (2002). Moreover, Lubik (2003), also using a discrete time specification, shows that the effects of capital stock dynamics in this context depend critically on the degree of strucural distortions in the economy.

${ }^{28}$ In line with this reasoning, Annicchiarico et al. (2005), using a discrete time version of Blanchard (1985), discuss monetary and fiscal interactions by means of stochastic simulations in which the Taylorprinciple plays a significant role. However, the paper does not discuss the role of government debt in a systematic way.
} 
introduce mechanisms for reinstating the Taylor principle in versions of the model which ignore fiscal policy.

\section{Conclusion}

This paper starts out from the observation that in the New Keynesian paradigm fiscal policy traditionally plays no prominent role. While monetary policy rules, typically specified as interest rate rules with feedbacks to endogenous variables like inflation or output, have been analyzed in great analytical detail, there is no similarly rich literature on the appropriate use of fiscal instruments. It is well understood that this asymmetric treatment is adequate in models in which fiscal policy acts through variations in lump-sum taxes in an environment of Ricardian equivalence, ensuring that the joint design problem of monetary and fiscal policy-making essentially reduces to two separable problems which can be recursively addressed. The main contribution of this paper is to show within a simple and tractable framework how this logic needs to be modified in an environment which departs from Ricardian equivalence, implying that equilibrium dynamics are driven by a genuine interaction of monetary and fiscal policy.

To this end, we develop a New Keynesian version of the model of Blanchard (1985) in which, assuming that all taxation is lump-sum, departures from Ricardian equivalence can be conveniently modelled through a change in the probability of death of consumers. If this probability is strictly positive (i.e. if consumers are 'non-Ricardian'), Ricardian equivalence ceases to hold and government debt turns into a relevant state variable which needs to be accounted for in the analysis of local equilibrium dynamics. Assuming simple policy feedback rules in the spirit of Leeper (1991), our analysis of local steady-state dynamics shows that there exist, depending on the assumed target level of government debt, two qualitatively distinct regimes characterized by 'low' and 'high' steady-state levels of debt. These regimes arise since wealth effects of government debt in the Euler equation lead to non-trivial demand and supply effects, which interact differently at different levels of steady-state debt and which are related to the endogeneity of the capital stock in the model of Blanchard. Specifically, our model implies that in the high (low) debt regime the degree of fiscal discipline, which is needed to ensure locally determinate dynamics, increases (decreases) if monetary policy becomes more active. More generally speaking, this leads to the conclusion that, if fiscal policy is non-neutral, meaningful characterizations of monetary and fiscal stabilization policies are conditional on the prevailing regime of the target level of government debt. If this dependence is not made explicit, policy recommendations may well be misleading.

These rich findings contrast strongly with an environment populated by 'Ricardian' consumers, characterized by a zero probability of death. Under this assumption, the wealth effect of government debt in the Euler equation vanishes and the economy converges against a Ramsey-economy characterized by Ricardian equivalence. Consequently, government debt is no longer an informative state variable and local steady-state dynamics can be assessed without reference to the target level of government debt. 


\section{Appendix}

\section{Appendix 1: Proof of Lemma 1}

Steady states of (24) and (25) satisfy

$$
\xi(\xi+\theta) \cdot \frac{k+b}{r(k)-\theta}=k^{1-\gamma}-\delta k-g, \quad \text { with: } b=\frac{\tau-g}{r(k)} .
$$

Hence,

$$
\begin{aligned}
\frac{d b}{d \tau} & =\frac{\partial b}{\partial \tau}+\frac{\partial b}{\partial k} \frac{\partial k}{\partial \tau} \\
& =\frac{1}{r}-\frac{\frac{b}{k} \gamma \frac{r+\delta}{r} \frac{\xi(\xi+\theta)}{r(r-\theta)}}{\left.\frac{d c}{d k}\right|_{(24)}-\left.\frac{d c}{d k}\right|_{(25)}}, \text { with: } \\
\left.\frac{d c}{d k}\right|_{(24)} & =\frac{r+\delta}{r-\theta} \gamma \frac{c}{k}+\frac{c}{k+b}+\gamma \frac{b}{k+b} \frac{c}{k} \frac{(r+\delta)}{r} \\
\left.\frac{d c}{d k}\right|_{(25)} & =(1-\gamma) \frac{y}{k}-\delta
\end{aligned}
$$

Assume $\tau=g \Leftrightarrow b=0$. Then

$$
\left.\frac{d c}{d k}\right|_{(24)}-\left.\frac{d c}{d k}\right|_{(25)}=\frac{r+\delta}{r-\theta} \gamma \frac{c}{k}-\left[(1-\gamma) \frac{y}{k}-\delta-\frac{c}{k}\right]=\frac{r+\delta}{r-\theta} \gamma \frac{c}{k}-\frac{1}{k}(g-\gamma y) .
$$

Hence, Assumption (A 1) is sufficient to ensure that at $\tau=g$ equation (24) intersects equation (25) from below, as required for steady states of type $E_{H}$. Moreover, $\left.\frac{d b}{d \tau}\right|_{\tau=g}=$ $\frac{1}{r}>0,\left.\frac{d b}{d \tau}\right|_{\tau \rightarrow \bar{\tau}} \rightarrow-\infty$, and

$$
\frac{d b}{d \tau} \mid=0 \Leftrightarrow \frac{c}{k+b}+\frac{r+\delta}{r-\theta} \gamma \frac{c}{k}-(1-\gamma) \frac{y}{k}+\delta=0,
$$

with (44) defining by continuity of all expressions implicitly a unique value $\tau^{*} \in(g, \bar{\tau})$ with associated value $b^{*}$ which maximizes steady-state debt.

\section{Appendix 2: Linearized inflation dynamics}

To establish equation (29) used in the main text we proceed in three steps. First, starting out from (18), the evolution of optimally adjusted prices $p(z)_{t}$ can be approximated to the first order as

$$
\widehat{p(z)}_{t}=\frac{p(z)_{t}-p(z)}{p(z)}=\int_{t}^{\infty}(r+\alpha)\left[\widehat{p}_{s}+\widehat{M C}_{s}\right] \cdot e^{-(r+\alpha)(s-t)} d s .
$$

Differentiating this expression with respect to time, using the Leibnitz rule, gives

$$
d \widehat{p(z)}_{t}=(r+\alpha)\left(\widehat{p(z)}_{t}-\widehat{p}_{t}-\widehat{M C}_{t}\right) .
$$


Second, the evolution of the aggregate price level (19) can be approximated as

$$
\left.\widehat{p}_{t}=\frac{p_{t}-p}{p}=\int_{-\infty}^{t} \alpha \widehat{p(z)}\right)_{s} \cdot e^{-\alpha(t-s)} d s
$$

Note that $d \widehat{p}_{t}=\frac{\dot{p}_{t}}{p} \equiv \pi_{t}$ and $d^{2} \widehat{p}_{t} \equiv d \pi_{t}$. Differentiating $\widehat{p}_{t}$ with respect to time gives

$$
d \widehat{p}_{t} \equiv \pi_{t}=\alpha\left(\widehat{p(z)}_{t}-\widehat{p}_{t}\right)
$$

i.e. inflation will be positive whenever 'newly adjusted prices rise relatively more strongly than average prices'. As regards changes in inflation, inflation accelerates $\left(d \pi_{t}=\dot{\pi}_{t}>0\right)$ whenever the 'inflation rate of newly set prices' $\left.(d \widehat{p(z)})_{t}\right)$ exceeds the (average) inflation rate $\left(d \widehat{p}_{t}=\pi_{t}\right)$, with $d \pi_{t}$ given by

$$
d \pi_{t}=\alpha\left[(r+\alpha)\left(\widehat{p(z)}_{t}-\widehat{p}_{t}-\widehat{M C}_{t}\right)-\alpha\left(\widehat{p(z)}_{t}-\widehat{p}_{t}\right)\right]=r \pi_{t}-\alpha(r+\alpha) \widehat{M C}_{t} .
$$

Third, combining (12), (16) and (17), marginal costs evolve approximately according to,

$$
\widehat{M C}_{t}=\gamma \widehat{w}_{t}+(1-\gamma) \widehat{p}_{t}^{k}=\gamma \widehat{k}_{t}+\frac{f^{M}}{r+\delta} \pi_{t}
$$

leading to

$$
d \pi_{t}=-\alpha(r+\alpha) \gamma \widehat{k}_{t}+\left[r-\alpha(r+\alpha) \frac{f^{M}}{r+\delta}\right] \pi_{t},
$$

which is equation (29) used in the main text.

\section{Appendix 3: Determinacy conditions under non-Ricardian consumers}

As referred to in the main text, the determinant of the matrix $J$ in (30) is given by

$$
\begin{aligned}
\operatorname{Det}(J) & =\left[r-f^{F}\right]\left[\sigma_{0}+\sigma_{1} f^{M}\right]+r \sigma_{2} f^{M}, \quad \text { with: } \\
\sigma_{0} & =(r-\theta) r\left[(1-\gamma) \frac{y}{k}-\delta-\frac{c}{k+b}\right] \\
\sigma_{1} & =\frac{\alpha(r+\alpha)(r-\theta)}{r+\delta}\left\{\frac{r+\delta}{r-\theta} \gamma \frac{c}{k}+\frac{c}{k+b}-(1-\gamma) \frac{y}{k}+\delta\right\} \\
& =\frac{\alpha(r+\alpha)(r-\theta)}{r+\delta}\left\{\frac{r+\delta}{r-\theta} \gamma \frac{c}{k}-\frac{\sigma_{0}}{(r-\theta) r}\right\} \\
\sigma_{2} & =\frac{1}{r} \xi(\xi+\theta) \frac{b}{c} \alpha(r+\alpha) \gamma \frac{c}{k} \\
& =\frac{\alpha(r+\alpha)(r-\theta)}{r+\delta}\left\{\gamma \frac{b}{k+b} \frac{c}{k} \frac{(r+\delta)}{r}\right\},
\end{aligned}
$$

where we use from $(24)$ the cashless steady-state condition $\xi(\xi+\theta)=(r-\theta) c /(k+b)$. From Appendix 1, note that

$$
\left.\frac{d c}{d k}\right|_{(24)}>\left.\frac{d c}{d k}\right|_{(25)} \Leftrightarrow \sigma_{1}+\sigma_{2}>0
$$


and $\tau=\tau^{*} \Leftrightarrow \sigma_{1}=0$, according to (44). Note that $\sigma_{2}>0$ is always satisfied, while the signs of $\sigma_{0}$ and $\sigma_{1}$ are a priori ambiguous. Consider the situation of a balanced primary budget with $\tau=g \Leftrightarrow b=0$. Then, $\left.\sigma_{0}\right|_{\tau=g}=\frac{(r-\theta) r}{k}[g-\gamma y]<0$ because of (A 1), implying $\left.\sigma_{1}\right|_{\tau=g}>0$. Rewrite $\sigma_{0}$ as $\sigma_{0}=(r-\theta) r\left[(1-\gamma) \frac{y}{k}-\delta-\frac{\xi(\xi+\theta}{r-\theta}\right]$ to see that $\sigma_{0}$ continuously rises in $\tau$, since both $r$ and $\frac{y}{k}$ rise in $\tau$. Starting out from $\tau=g$ consider a rise in $\tau$, holding $g$ fixed, such that $\tau \in(g, \bar{\tau}) \Leftrightarrow b \in\left(0, b^{*}\right)$. Note that if $\tau=\bar{\tau} \Rightarrow b=\bar{b}$, then $\left.\frac{d c}{d k}\right|_{(24)}=\left.\frac{d c}{d k}\right|_{(25)}$, i.e. $\sigma_{1}=-\sigma_{2}<0$. This implies that as $\tau$ rises from $g$ to $\bar{\tau}$ there exist by continuity three distinct qualitative patterns of

$$
\operatorname{Det}(J)=0 \Leftrightarrow f^{F}=r\left(1+\frac{\sigma_{2} f^{M}}{\sigma_{0}+\sigma_{1} f^{M}}\right)
$$

characterized by

(a) $\tau \in\left(g, \tau_{1}\right) \Rightarrow b \in\left(0, b_{1}\right): \sigma_{0}<0, \sigma_{1}>0, \sigma_{2}>0$;

(b) $\tau \in\left(\tau_{1}, \tau^{*}\right) \Rightarrow b \in\left(b_{1}, b^{*}\right): \sigma_{0}>0, \sigma_{1}>0, \sigma_{2}>0$;

(c) $\tau \in\left(\tau^{*}, \bar{\tau}\right) \Rightarrow b \in\left(\bar{b}, b^{*}\right): \sigma_{0}>0, \sigma_{1}<0, \sigma_{2}>0$,

with representations as shown in Figures $3(a)-(c)$.

As regards the sufficient condition for determinacy, note that

$$
\operatorname{Det}(J)>0, \operatorname{Tr}(J)<0
$$

implies that eigenvalues must follow the pattern $\lambda_{1}>0, \lambda_{2}>0, \lambda_{3}<0, \lambda_{4}<0$ or, alternatively, $\lambda_{1}<0, \lambda_{2}<0, \lambda_{3}<0, \lambda_{4}<0$. However, the structure of $J$ in (30) is such that the second pattern of four negative eigenvalues can never occur. To prove this, we invoke the 'quasi-negative definiteness' criterion as stated, for example, in Gandolfo (1996, p.252) which calls for forming the matrix $B=\left(J+J^{\prime}\right) / 2$, i.e.

$$
B=\left[\begin{array}{cccc}
r-f^{F} & -\frac{1}{2} \xi(\xi+\theta) \frac{b}{c} & 0 & \frac{1}{2} f^{M} \\
-\frac{1}{2} \xi(\xi+\theta) \frac{b}{c} & r-\theta & -\frac{1}{2}\left[\frac{c}{k}+\frac{\xi(\xi+\theta) k}{c}\right] & \frac{1}{2} f^{M} \\
0 & -\frac{1}{2}\left[\frac{c}{k}+\frac{\xi(\xi+\theta) k}{c}\right] & (1-\gamma) \frac{y}{k}-\delta & -\frac{1}{2} \alpha(r+\alpha) \gamma \\
\frac{1}{2} f^{M} & \frac{1}{2} f^{M} & -\frac{1}{2} \alpha(r+\alpha) \gamma & r-\alpha(r+\alpha) \frac{f^{M}}{r+\delta}
\end{array}\right]
$$

A set of necessary and sufficient conditions for all four eigenvalues of $J$ to be negative is that the leading minors of $B$ alternate in sign, beginning with minus. In our case, the first leading minor will only be negative if $r<f^{F}$. However, this implies, since $r>\theta$, that the second leading minor must also be negative, ruling out the possibility of four negative eigenvalues. Hence, $\operatorname{Det}(J)>0, \operatorname{Tr}(J)<0$ implies $\lambda_{1}>0, \lambda_{2}>0, \lambda_{3}<0, \lambda_{4}<0$.

\section{Appendix 4: Endogenous labour supply of Ricardian consumers $(\xi=0)$ a) Steady state discussion}

Extending the analysis in Section 3.1, $w$ and $r$ are now a function of the capital intensity $(k / n)$, i.e.

$$
w=\frac{\rho-1}{\rho} \gamma\left(\frac{k}{n}\right)^{1-\gamma}=w\left(\frac{k}{n}\right) \text { and } \quad r=\frac{\rho-1}{\rho}(1-\gamma)\left(\frac{k}{n}\right)^{-\gamma}-\delta=r\left(\frac{k}{n}\right) .
$$


Assuming $\xi=0$, the aggregate consumer Euler equation (10) implies $r(k / n)=\theta$, i.e. the steady-state capital intensity and the two factor prices $w$ and $r$ are uniquely pinned down by $\theta$. The two remaining steady-state relationships are given by the aggregate resource constraint

$$
c=n^{\gamma} k^{1-\gamma}-\delta k-g=n\left[\left(\frac{k}{n}\right)^{1-\gamma}-\delta \frac{k}{n}\right]-g
$$

and the labour supply condition

$$
n=1-\left(\frac{c}{w}\right)^{\frac{1}{\psi}} \Leftrightarrow c=w(1-n)^{\psi} .
$$

With $w$ and $k / n$ being fixed by $\theta$, these two equations have two unknowns, i.e. $c$ and $n$. Combining the two equations yields an expression in $n$, i.e.

$$
w(1-n)^{\psi}=n\left[\left(\frac{k}{n}\right)^{1-\gamma}-\delta \frac{k}{n}\right]-g .
$$

Consider $n \in(0,1)$. Then, the LHS falls continuously in $n$, while the RHS rises continuously in $n$, i.e. for appropriate values of $g$ there exists a unique steady state with positive activity levels.

\section{b) Derivation of the transition matrix $J$ in equation (42)}

Notice that the first two rows of (42), describing the dynamics of $\widehat{b}_{t}$ and $\widehat{c}_{t}$, are the same as in (31).

Linearized capital stock dynamics:

To derive the third row of (42), describing the dynamics of $\widehat{k}_{t}$, we start out from the original law of motion $d k_{t}=n_{t}^{\gamma} k_{t}^{1-\gamma}-\delta k_{t}-c_{t}-g$ which can be approximated as

$$
d \widehat{k}_{t}=-\frac{c}{k} \widehat{c}_{t}+\left[(1-\gamma) \frac{y}{k}-\delta\right] \widehat{k}_{t}+\gamma \frac{y}{k} \widehat{n}_{t}
$$

To substitute out for $\widehat{n}_{t}$, linearize the two new equations (39) and (41), yielding $\widehat{c}_{t}-\widehat{w}_{t}=$ $-\varepsilon \widehat{n}_{t}$ and $\widehat{k}_{t}-\widehat{n}_{t}+\frac{f^{M}}{\theta+\delta} \pi_{t}=\widehat{w}_{t}$. These two equations can be combined to give

$$
\widehat{n}_{t}=\frac{1}{1+\varepsilon}\left[-\widehat{c}_{t}+\widehat{k}_{t}+\frac{f^{M}}{\theta+\delta} \pi_{t}\right]
$$

leading to

$$
d \widehat{k}_{t}=-\left[\gamma \frac{1}{1+\varepsilon} \frac{y}{k}+\frac{c}{k}\right] \widehat{c}_{t}+\left[\gamma \frac{1}{1+\varepsilon} \frac{y}{k}+(1-\gamma) \frac{y}{k}-\delta\right] \widehat{k}_{t}+\gamma \frac{1}{1+\varepsilon} \frac{y}{k} \frac{f^{M}}{\theta+\delta} \pi_{t}
$$

which corresponds to the third row of (42).

Linearized inflation dynamics:

To derive the fourth row of (42), describing the dynamics of $\pi_{t}$, we start out from equation (45) derived in Appendix 2, i.e.

$$
d \pi_{t}=\theta \pi_{t}-\alpha(\theta+\alpha) \widehat{M C}_{t},
$$


and recognize that with a flexible labour supply marginal costs evolve approximately according to $\widehat{M C}_{t}=\gamma \widehat{w}_{t}+(1-\gamma) \widehat{p}_{t}^{k}=\gamma\left(\widehat{k}_{t}-\widehat{n}_{t}\right)+\frac{f^{M}}{\theta+\delta} \pi_{t}$, where we have used $\widehat{k}_{t}-\widehat{n}_{t}+$ $\frac{f^{M}}{\theta+\delta} \pi_{t}=\widehat{w}_{t}$. Substituting out for $\widehat{n}_{t}$ from above, yields

$$
\widehat{M C}_{t}=\gamma \frac{1}{1+\varepsilon} \widehat{c}_{t}+\gamma \frac{\varepsilon}{1+\varepsilon} \widehat{k}_{t}+\frac{f^{M}}{\theta+\delta}\left(1-\gamma \frac{1}{1+\varepsilon}\right) \pi_{t}
$$

Hence,

$$
d \pi_{t}=-\alpha(\theta+\alpha) \gamma \frac{1}{1+\varepsilon} \widehat{c}_{t}-\alpha(\theta+\alpha) \gamma \frac{\varepsilon}{1+\varepsilon} \widehat{k}_{t}+\left\{\theta-\alpha(\theta+\alpha)\left[1-\gamma \frac{1}{1+\varepsilon}\right] \frac{f^{M}}{\theta+\delta}\right\} \pi_{t},
$$

which corresponds to the fourth row of (42).

\section{References}

[1] Annicchiarico, B., Giammarioli, N., and Piergallini, A., Fiscal policy in a monetary economy with capital and finite lifetime, mimeo, 2005.

[2] Ascari, G. and Rankin, N., Perpetual youth and endogenous labour supply: a problem and a possible solution, ECB Working Paper Series, 346, 2004.

[3] Benassy, J.-P., Interest rate rules, price determinacy and the value of money in a non-Ricardian world, Review of Economic Dynamics, 8, 651-667, 2005.

[4] Benhabib, J., Schmitt-Grohé, S., and Uribe, M., The perils of Taylor rules, Journal of Economic Theory, 96, 40-69, 2001(a).

[5] Benhabib, J., Schmitt-Grohé, S., and Uribe, M., Monetary policy and multiple equilibria, American Economic Review, 91, 1, 167-186, 2001(b).

[6] Benhabib, J., Carlstrom, C. and Fuerst, T., Journal of Economic Theory, 123, 1-3, 2005.

[7] Bernanke, B. and Woodford, M., Inflation forecasts and monetary policy, Journal of Money, Credit, and Banking, 29, 4, 653-84, 1997.

[8] Blanchard, O., Debt, deficits, and finite horizons, Journal of Political Economy, 93/2, 223-247, 1985.

[9] Calvo, G., Staggered prices in a utility-maximizing framework, Journal of Monetary Economics, 12, 983-98, 1983.

[10] Canzoneri, M. and Diba, B., Interest rate rules and price determinacy: the role of transaction services of bonds, Journal of Monetary Economics, 52, 329-343, 2005.

[11] Carlstrom, T. and Fuerst, T., Timing and real indeterminacy in monetary models, Journal of Monetary Economics, 47, 285-298, 2001. 
[12] Carlstrom, T. and Fuerst, T., Investment and interest rate policy: a discrete time analysis, Journal of Economic Theory, 123, 4-20, 2005.

[13] Chadha, J. and Nolan, C., Optimal simple rules for the conduct of monetary and fiscal policy, Journal of Macroeconomics, forthcoming, 2006.

[14] Clarida, R., Gali, J., and Gertler, M., The science of monetary policy: a new Keynesian perspective, Journal of Economic Literature, 37, 1661-1707, 1999.

[15] Clarida, R., Gali, J., and Gertler, M., Monetary policy rules and macroeconomic stability: evidence and some theory, Quarterly Journal of Economics, 115, 147-80, 2000.

[16] Cushing, M., The indeterminacy of prices under interest rate pegging: The nonRicardian case, Journal of Monetary Economics, 44, 131-148, 1999.

[17] Davig, T., and Leeper, E., Fluctuating macro policies and the fiscal theory, mimeo, 2005.

[18] Dupor, B., Investment and interest rate policy, Journal of Economic Theory, 98, 85-113, 2001.

[19] Edge, R. and Rudd, J., Taxation and the Taylor principle, Finance and Economics Discussion Series 2002-51. Washington: Board of Governors of the Federal Reserve System, 2002.

[20] Gali, J., López-Salido, J., and Vallés, J., Rule of thumb consumers and the design of interest rate rules, Journal of Money, Credit, and Banking, 36, 4, 739-764, 2004.

[21] Gandolfo, G., Economic Dynamics, Third edition, Springer Verlag, 1996.

[22] Kerr, W. and King, R., Limits on interest rate rules in the IS model, Economic Quarterly, 82, 2, 47-75, 1996.

[23] Leeper, E., Equilibria under 'active' and 'passive' monetary and fiscal policies, Journal of Monetary Economics, 27, 129-147, 1991.

[24] Leith, C. and Wren-Lewis, S., Interactions between monetary and fiscal policy rules, Economic Journal, 110, C93-C108, 2000.

[25] Li, H., Inflation determination under a Taylor rule: consequences of endogenous capital accumulation, mimeo, 2002.

[26] Linnemann, L., Interest rate policy, debt, and indeterminacy with distortionary taxation, Journal of Economic Dynamics and Control, forthcoming, 2006.

[27] Lubik, T., Investment spending, equilibrium indeterminacy, and the interactions of monetary and fiscal policy, mimeo, 2003. 
[28] Michel, P., von Thadden, L., and Vidal, J.-P., Debt stabilizing fiscal rules, ECB Working Paper Series, 576, 2006.

[29] Schmitt-Grohé, S. and Uribe, M., Optimal simple and implementable monetary and fiscal rules, mimeo, 2004.

[30] Sims, C., A simple model for study of the determination of the price level and the interaction of monetary and fiscal policy, Economic Theory, 4, 381-99, 1994.

[31] Sims, C., The precarious fiscal foundations of EMU, mimeo, 1998.

[32] Taylor, J., Discretion versus policy rules in practice, Carnegie Rochester Conference Series on Public Policy, 39, 195-214, 1993.

[33] Weil, P., Is money net wealth ?, International Economic Review, 37-53, 32, 1991.

[34] Woodford, M., Monetary policy and price level determinacy in cash-in-advance economy, Economic Theory, 345-380, 1994.

[35] Woodford, M., Interest and prices, Foundations of a theory of monetary policy, Princeton University Press, 2003. 


\section{European Central Bank Working Paper Series}

For a complete list of Working Papers published by the ECB, please visit the ECB's website (http://www.ecb.int)

594 “The euro's trade effects” by R. Baldwin, comments by J. A. Frankel and J. Melitz, March 2006

595 "Trends and cycles in the euro area: how much heterogeneity and should we worry about it?" by D. Giannone and L. Reichlin, comments by B. E. Sørensen and M. McCarthy, March 2006.

596 "The effects of EMU on structural reforms in labour and product markets" by R. Duval and J. Elmeskov, comments by S. Nickell and J. F. Jimeno, March 2006.

597 "Price setting and inflation persistence: did EMU matter?" by I. Angeloni, L. Aucremanne, M. Ciccarelli, comments by W. T. Dickens and T. Yates, March 2006.

598 "The impact of the euro on financial markets" by L. Cappiello, P. Hördahl, A. Kadareja and S. Manganelli, comments by X. Vives and B. Gerard, March 2006.

599 "What effects is EMU having on the euro area and its Member Countries? An overview" by F. P. Mongelli and J. L. Vega, March 2006.

600 "A speed limit monetary policy rule for the euro area” by L. Stracca, April 2006.

601 "Excess burden and the cost of inefficiency in public services provision" by A. Afonso and V. Gaspar, April 2006.

602 "Job flow dynamics and firing restrictions: evidence from Europe" by J. Messina and G. Vallanti, April 2006.

603 “Estimating multi-country VAR models" by F. Canova and M. Ciccarelli, April 2006.

604 "A dynamic model of settlement" by T. Koeppl, C. Monnet and T. Temzelides, April 2006.

605 “(Un)Predictability and macroeconomic stability” by A. D’Agostino, D. Giannone and P. Surico, April 2006.

606 "Measuring the importance of the uniform nonsynchronization hypothesis" by D. A. Dias, C. Robalo Marques and J. M. C. Santos Silva, April 2006.

607 "Price setting behaviour in the Netherlands: results of a survey" by M. Hoeberichts and A. Stokman, April 2006.

608 "How does information affect the comovement between interest rates and exchange rates?" by M. Sánchez, April 2006.

609 "The elusive welfare economics of price stability as a monetary policy objective: why New Keynesian central bankers should validate core inflation” by W. H. Buiter, April 2006.

610 "Real-time model uncertainty in the United States: the Fed from 1996-2003" by R. J. Tetlow and B. Ironside, April 2006. 
6 II "Monetary policy, determinacy, and learnability in the open economy" by J. Bullard and E. Schaling, April 2006.

612 "Optimal fiscal and monetary policy in a medium-scale macroeconomic model" by S. Schmitt-Grohé and M. Uribe, April 2006.

613 "Welfare-based monetary policy rules in an estimated DSGE model of the US economy" by M. Juillard, P. Karam, D. Laxton and P. Pesenti, April 2006.

$6 / 4$ "Expenditure switching vs. real exchange rate stabilization: competing objectives for exchange rate policy” by M. B. Devereux and C. Engel, April 2006.

615 "Quantitative goals for monetary policy” by A. Fatás, I. Mihov and A. K. Rose, April 2006.

616 "Global financial transmission of monetary policy shocks" by M. Ehrmann and M. Fratzscher, April 2006.

617 “New survey evidence on the pricing behaviour of Luxembourg firms” by P. Lünnemann and T. Y. Mathä, May 2006.

618 "The patterns and determinants of price setting in the Belgian industry" by D. Cornille and M. Dossche, May 2006.

619 "Cyclical inflation divergence and different labor market institutions in the EMU" by A. Campolmi and E. Faia, May 2006.

620 "Does fiscal policy matter for the trade account? A panel cointegration study" by K. Funke and C. Nickel, May 2006.

621 "Assessing predetermined expectations in the standard sticky-price model: a Bayesian approach" by P. Welz, May 2006.

622 "Short-term forecasts of euro area real GDP growth: an assessment of real-time performance based on vintage data" by M. Diron, May 2006.

623 "Human capital, the structure of production, and growth" by A. Ciccone and E. Papaioannou, May 2006.

624 "Foreign reserves management subject to a policy objective" by J. Coche, M. Koivu, K. Nyholm and V. Poikonen, May 2006.

625 "Sectoral explanations of employment in Europe: the role of services" by A. D'Agostino, R. Serafini and M. Ward-Warmedinger, May 2006.

626 "Financial integration, international portfolio choice and the European Monetary Union" by R. A. De Santis and B. Gérard, May 2006.

627 "Euro area banking sector integration: using hierarchical cluster analysis techniques" by C. Kok Sørensen, J. M. Puigvert Gutiérrez, May 2006.

628 "Long-run money demand in the new EU Member States with exchange rate effects" by C. Dreger, H.-E. Reimers and B. Roffia, May 2006. 
629 "A market microstructure analysis of foreign exchange intervention" by P. Vitale, May 2006.

630 “Implications of monetary union for catching-up member states” by M. Sánchez, May 2006.

63I "Which news moves the euro area bond market?" by M. Andersson, L. J. Hansen and S. Sebestyén, May 2006.

632 "Does information help recovering structural shocks from past observations?" by D. Giannone and L. Reichlin, May 2006.

633 "Nowcasting GDP and inflation: the real-time informational content of macroeconomic data releases" by D. Giannone, L. Reichlin and D. H. Small, May 2006.

634 "Expenditure reform in industrialised countries: a case study approach" by S. Hauptmeier, M. Heipertz and L. Schuknecht, May 2006.

635 "Identifying the role of labor markets for monetary policy in an estimated DSGE model" by K. Christoffel, K. Kuester and T. Linzert, June 2006.

636 "Exchange rate stabilization in developed and underdeveloped capital markets" by V. Chmelarova and G. Schnabl, June 2006.

637 "Transparency, expectations, and forecasts" by A. Bauer, R. Eisenbeis, D. Waggoner and T. Zha, June 2006.

638 "Detecting and predicting forecast breakdowns" by R. Giacomini and B. Rossi, June 2006.

639 "Optimal monetary policy with uncertainty about financial frictions" by R. Moessner, June 2006.

640 “Employment stickiness in small manufacturing firms" by P. Vermeulen, June 2006.

64 I "A factor risk model with reference returns for the US dollar and Japanese yen bond markets" by C. Bernadell, J. Coche and K. Nyholm, June 2006.

642 "Financing constraints and firms' cash policy in the euro area" by R. Pál and A. Ferrando, June 2006.

643 "Inflation forecast-based-rules and indeterminacy: a puzzle and a resolution" by P. Levine, P. McAdam and J. Pearlman, June 2006.

644 "Adaptive learning, persistence, and optimal monetary policy" by V. Gaspar, F. Smets and D. Vestin, June 2006.

645 “Are internet prices sticky?” by P. Lünnemann and L. Wintr, June 2006.

646 "The Dutch block of the ESCB multi-country model" by E. Angelini, F. Boissay and M. Ciccarelli, June 2006.

647 "The economic effects of exogenous fiscal shocks in Spain: a SVAR approach" by F. de Castro Fernández and P. Hernández de Cos, June 2006.

648 "Firm-specific production factors in a DSGE model with Taylor price setting" by G. de Walque, F. Smets and R. Wouters, June 2006. 
649 "Monetary and fiscal policy interactions in a New Keynesian model with capital accumulation and non-Ricardian consumers" by C. Leith and L. von Thadden, June 2006. 
